\title{
15.
}

\section{Zrei Adulefizhü̈djer.}

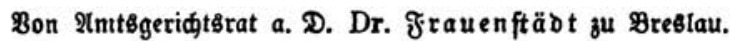

Die menngleid nidłt meb̆r volzäblige, immerhin abet nod redt

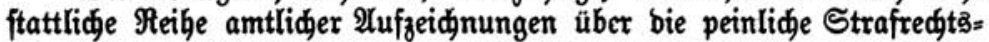

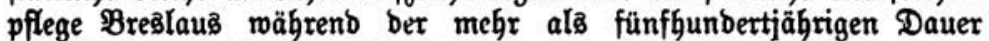

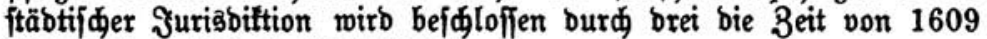
bis 1800 umfaffenbe Palefizbüder.')

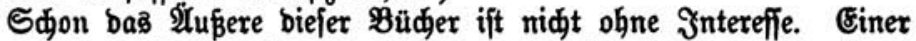
bereits im 16. Jahrbunbert aufgefommenen Bemohnheit entiprecheno find bie vollzogenen Strafen am Borberranbe finnbilblich bargeftellt; in ben beiben erften Bänden allerbings nur in febr primitiver, ted =

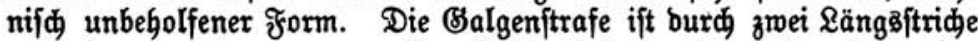
uno einen barüber gezogenen Queritrid mit baran hängenbem figürḑen angebeutet, bie einfade Enthauptung burd ein blantes nad oben ge= ridtetea Sdimert ober ein Beil; bie qualifizierte burd ein Sdpert uno ein Beftell, an beffen oberer Şälite fich zmei Sreife, ein grö́perer Gorizontaler unb ein fleinerer vertifaler befinden, bie ein $\Re$ ab mit bem

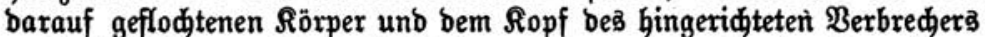
vorítellen follen. Dả̆ Entränfen wirb angebeutet burd megrere mellenförmig burdeinanderlaufende Stride, ber Feuertob burd einen

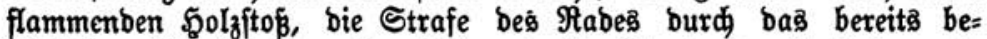
furrebene Breftell, aber ogne Sdymert, bie Strafe ber \&andeảverwei=

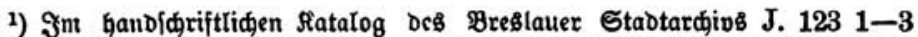
verzeidnet. $\mathfrak{A}_{\mathfrak{n}}$ früberen $\mathfrak{P a l e f i z b u ̈ i d e r n ~ f i n d ~ n u r ~ n o d ~ D i e ~ H i r s u t a ~ b i l l a ~ n o v a ~}$ von 1448-1509 und die Hirsuta hilla tertia von 1510-1525 vorbanden, Deren

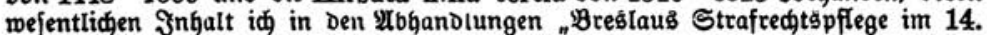
bis 16. Jahrbunbert" (Z X 1-35, 229-250) uno "Das Slaunertum Des Deut: ficen פittelalters" (Z XVIII 331-352) zur Darjtellung gebradt Gabe. Bon

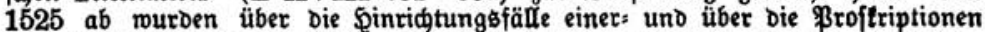

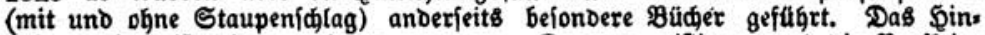
riđ̆tunģ̄bud ift leider verloren gegangen. Dagegen eriftieren nod Die \$roffrips tionsbitder für 1525-1582 und von 1582-1609. In Das lę̧tgenannte trugen von 1593 ab bie Stadtjめreiber aud Die Sinridtungsfälle ein. E\& fübrt Daher

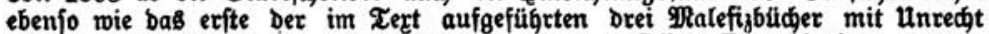
Den auf Dem Einbandoedel vorgebrudten शamen "Liber Proscriptionum", Da es alle 2 rten von Dralefizfälten umfaßst. 


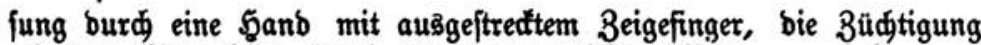
mit bem Staupbejen burd eine emporgeridtete Rute.

Die vorftehenden Symbole fesen fich biz zum Blatt 9 ber britten

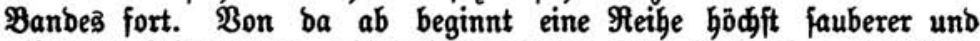

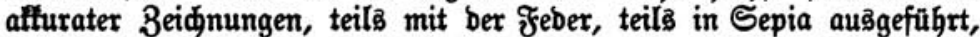
bie von ben verídiebenen Erefutionen und ben babei benubten ßor= riditungen und Berfizeugen eine gute Borftellung geben. So folgen

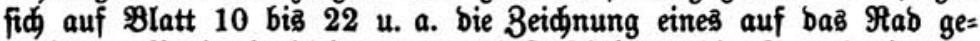
flodtenen Berbrederleidnams; zwei Tujdbilber, bie Staupfäule bar= ftellenb, an ber ber Sdarfridter an zwei halbentfleibeten frauens= perfonen bie Strafe ber Stäupung vollzieht, fowie zmei anore $T$ uf bilber, auf benen bie Entbauptung einer Frauensperfon bargeftellt ift. 2)uf bem exften Pilbe fitgt bie Delinquentin mit verbunbenen 2 tugen auf einem Stuble mit $\Re$ tüd= und Seitenlegnen, hinter ihr ftegt ber

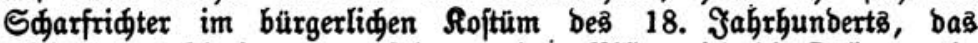

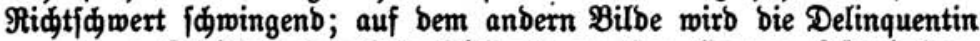

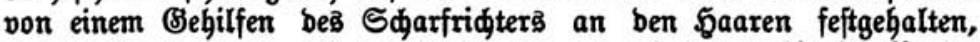

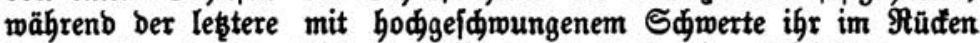

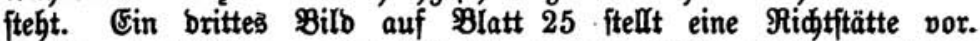

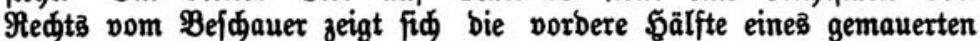

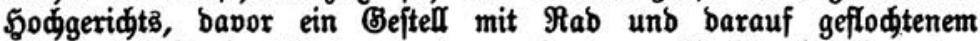
Rörper, linfas im Borbergrunbe, auf einem Stuble befeftigt, ber

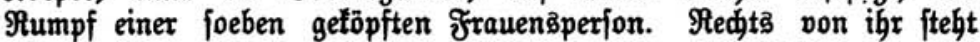
mit gefenftem Sdyert ber Sdarfridter, linfs jein Bebilfe in Iangem Bebrod und Stulpenftiefeln, ber nidt fidtbaren 3ujwauermenge bas Saupt ber Berbredjerin zeigend. Ditten über biefer Szene erblidt man baß Bruftbilb ber 5ुingeridteten in Mebaillonform. Sie hieß शaria Jofefa Sdubert, biente in Breșlau als Rödin bei einer Syerridaft ber befferen Stänbe und hatte, um fid wegen veridiebener vermeintlider Beleibigungen zu räden, am 15. Oftober 1797 bem vierjäbrigen Söhnden ibrer Sherridaft mit einem Dleffer eine abjolut

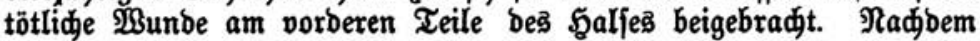
fie im Inftanzen= und Bnabenwege vergebens eine Milberung besె gegen fie ergangenen Tobesెurteilä bahin zu erroirfen verjudit hatte,

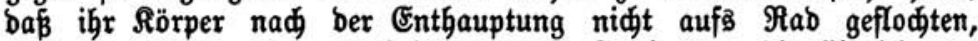
fonbern beerbigt würbe, exfolgte am 20. J゙uni 1800 bie f̧inridtung. Der bamalige Sdarfridter Thienel vollzog an ihr, mie bas MRalefiz=

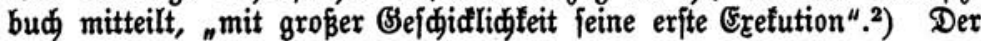

2) Das Sdjarfridteramt (4)eint fid in ber familie Thienel vererbt ou

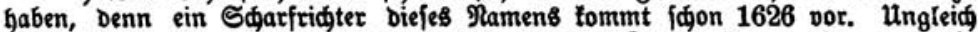

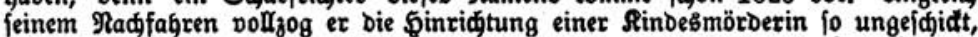

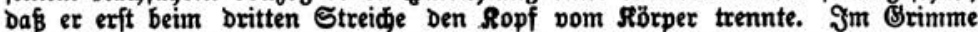

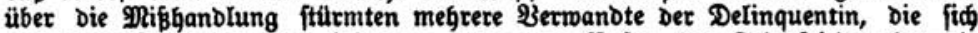

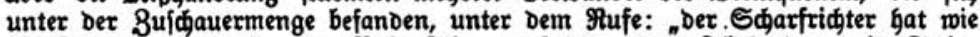
ein Sdelm geridtet", Den Rabenftein, verfolgten Den Ffliegenden mit Stein= mürfen bis in bie Staot. und f́dtugen ign bort zu Tobe. Der \$auptthäter, Der

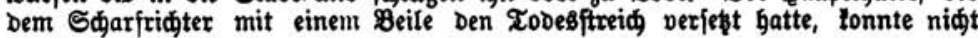




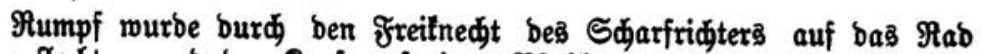

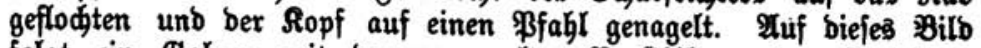
folgt ein Balgen mit barangenagelten Bruftbildern ber flüdtigen, wegen betrügliden Banterutts in contumaciam verurteilten Delin: quenten und am Sdlús zwei Tujळbilber in Sepia. Das erfte eine

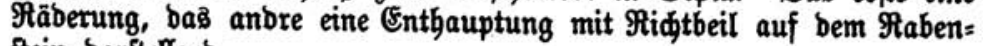
ftein barftellento.

Die Malefizbüder find von ben Stabtidreibern verfaßst unb be

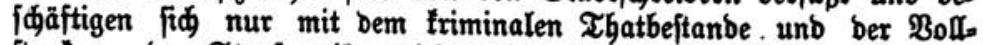
ftredung ber Strafurteile, nidt mit beren juriftifden Pegrïnbung.

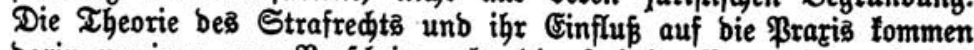
barin meniger zum Borfdein, als bie fogialen Borurteile und bie manderlei Sđrutlen uno Bertehrtheiten ber bamaligen Strafredts.

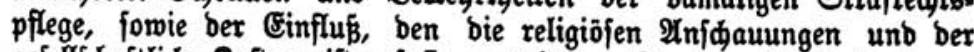
gefelfidaftlidje Raftengeift auf fie ausübten. Durd meldje fonberbaren

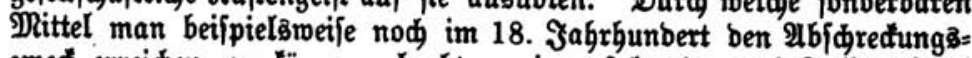
zợ erreiden zu fönnen glaubte, zeigen folgenbe zmei fălle: 3 mei junge Reute von nod, nidt zwanzig Jahren waren 1713 wegen

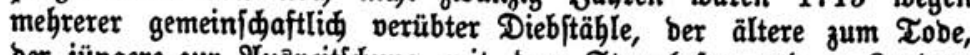

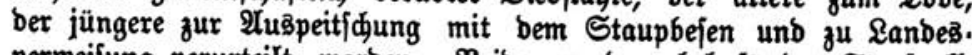
verweifung verurteilt worben. Beibe wurben behufs̄ ber Strafpoll= ftređung gleidzeitig aus beim Stabthaufe vorgeführt. ",Irrs fie zum

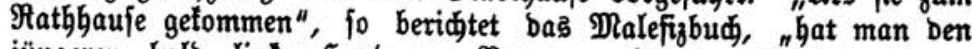
jüngeren bald linter אुand zum ßranger gefübrt, entfleibet unb ge=

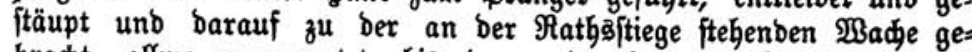
bradt, allwo er gewartet, bis ber anbre heruntergetommen, ba fie bann ferncr bis auf bas Sodggeridit hinter einanber gegangen, wo= felbft ber jüngere zufeben mưffen, wie ber anbre " "ziemlid langiam" am Balgen verenbete". In bem zmeiten fralle pon 1727 murben

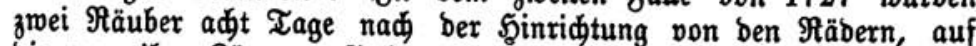

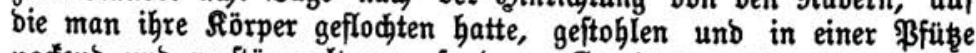
nadend und verftümmelt vorgefunden. \$ङ hätte nahe gelegen, bie ¿eidname zu verfdarren, ftatt beffen bradte man fie wieber auf bas

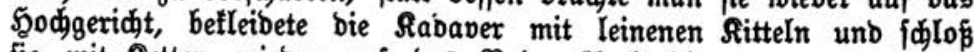

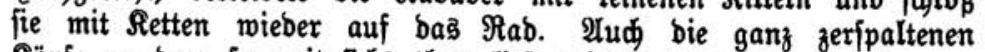
Röpfe murben, fo weit fids thun ließs, wieber obenauf genagelt.

Sdion am Sdluffe meiner थbhanblung über "Breălaus Straf:

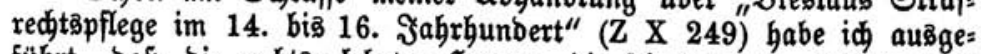

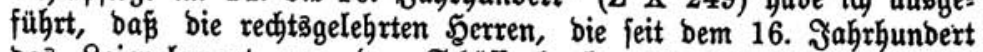
bå Saienelement von ber Sđöffenbanf verbrängten, mit nidten

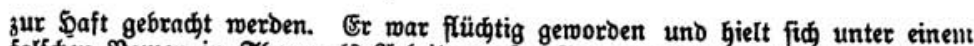

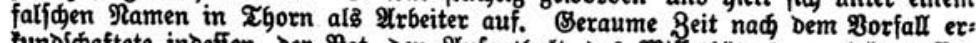

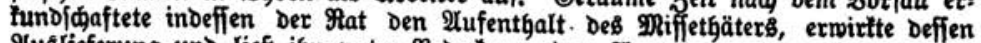

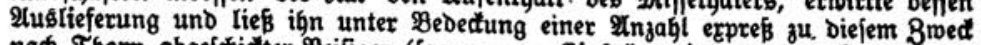

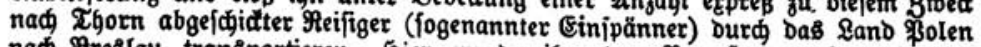
naळ Dresిlau transportieren. Sier murbe igm ber \$rojeß gemadit und bas Todesiurteil Durd Entbauptung volfogen. 
Gumaner und liberaler gerwejen feien alä ihre Borgänger aủ bem Raienftande. und aufgetlärtcr find fie aud nidgt gemefen. Nad, einem Şerenprozeß miro man in ben Malefizbüdjern zwar vergeblid, fuden. Aber ein Berbienf́t besె Sđjöffenftuhla war bas nidt, benn

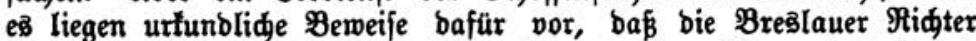
mit ber ganzen bamaligen Juriftenmelt unter bem Banne bes ફুeren= wahns ftanben.

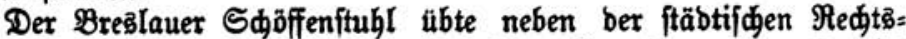

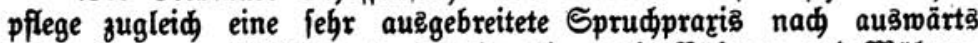

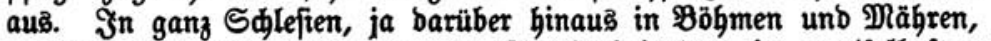
wanbten fid \$rivatperionen und Beridtabehörben in zweifelgaften

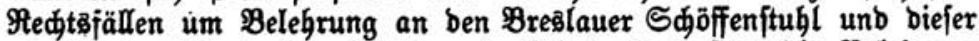
exteilte in fdmebenden Bivil= und Rriminalprozeffen bie Belehrung

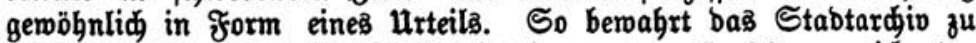
Bres̆lau einen im Şanbfdriftenfatalog unter J. 98 verzeidneten

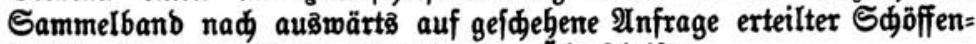
iprüde, in bem auf S. 29 unter ber tuberidrift:

"Strafe einer ßerfon, fo mit Bift, Bauberei umgangen und mit bem Teufel zu thun gebabt",

unb unter Borausfdictung ber ber Delinquentin (ber Efhefrau eines

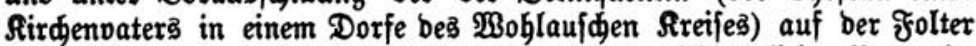

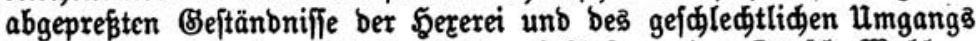

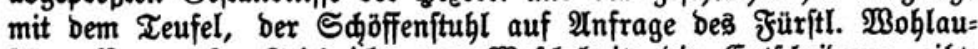

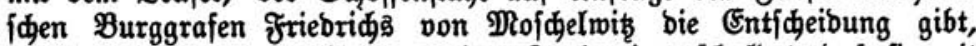
Delinquentin habe mit ihrer verübten 3auberei veridulbet, baß fie mit bem freuer vom Reben zum Tobe gebract und zu थ્fje verbrannt

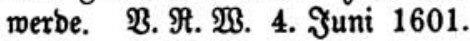

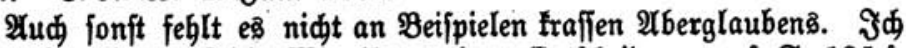

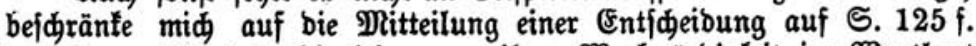
bes Sammelbandeș, bie iథ wegen ihrer Merfwürbigfeit im $\mathfrak{B}_{0}$ rtlaut folgen laffe.

代berfdrift: Fine Pago gat ein Sdlof zugefdloffen in ber Rirchen, aIs man ein \$aar Éheleute getrauet, hernad ift ber Bräu= tigam geftorben.

Quid juris.

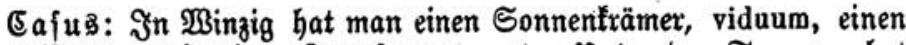
ftarfen Pann, mit einer Jैungfer getrauet. Unnter ber $\mathfrak{T}$ rauung bat eine Magd ein Sd)loß̄ (sc. eine Borlegefdloß̄) zuge\{dloffen. Wseil man aber शadridtunge (sc. erhalten) baß bieje Pago fid zuvor mit zweien Beibsperfonen von biefen Sachen unterrebet, hat man fie alle, - nađbbem biejer Bräutigam etlide Tage barauf geftorben uno über b̆̈fe Reute gefdrieen, bie eả ihm gemadit haben: Sponsa etiam fassa, ipsum non potuisse secum babere rem, sed dixisse, sibi non ita fuisse cum priore conjuge - vorgeforbert. Die Mago hat es be=

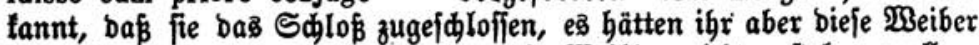

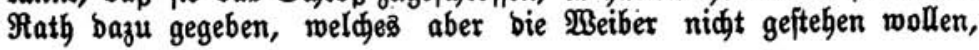


jonbern nur bies̉ befannt, berfelbe Präutigam hätte bei ihnen auథ früher angejdlagen, uno fid berübmt, velle se egregium praestare virum in re venerea etc. $\mathfrak{u}$ nd als ex hernad wäre ein Präutigam gewejen, hätten fie untereinander nid̆t megr als fo viel gerebet, er wäre werth,

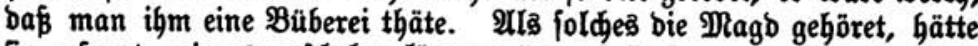
fie gefragt, wie es gefdegen fönnte; barauf fie ferner geredet, fie bätte gegört, wenn man unter ber Trauung ein Sdilok zufdiliebe, fo tönne man einem hierburd, eine Püberei thun, unb fo bas Sdloß ins $23 a f f e r$ geworfen mürbe, fo wäre einem ni⿻ы mehr zu helfen, fonbern müpte fterben. Sie hätten aber bie Magb mit niditen angefitiftet.

भif biefen Beridit hat man fid folgenden Miffivo vergliden.

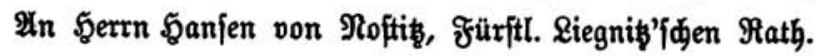

29. Ipril 1603.

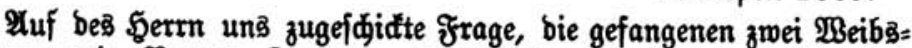

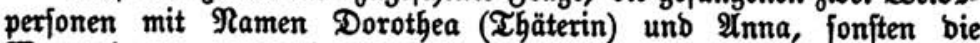
Bagnerin genannt und berfelben vorm $\Re$ athe und Beridjte zu Binzig gethane 2 uşfage betreffent unb begebrtent geridtliden unterridt, wären wir wohl gemeinet, ben Sুerrn bem Begebren nad aläbalb zu

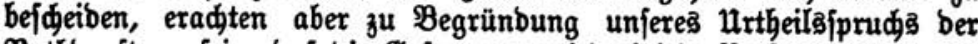
Rothburft zu fein, bá bie \&efangenen, jebod jebe ßerion abjonberlid (b. দ̆. niøt im Beifein ber anbern) nođ̆ einmal mil Bebräuung und Borftellung beßె Sdarfridtersె (b. h. ber Tortur), bod nod zur Beit ohne ßeinlides 2 nfftrengen umb bie ganze Bef́dulbigunge unb afle

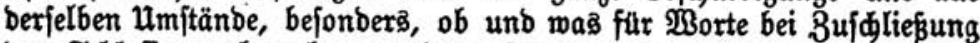
beä Sdloffes gebraudjet worben, fowohl, warum bas Sdloß ins Baffer gemorfen werben follen, im Ernft eraminiret und befraget

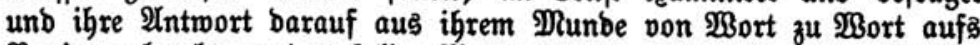
Bapier gebradt werben foll. Benn foldes gejdehen und uns ibre 2̂uşagen nodmalä zugefendet fein werben, fo wollen wir unsె nad

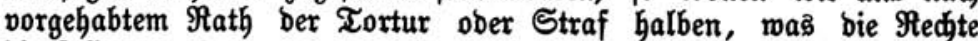

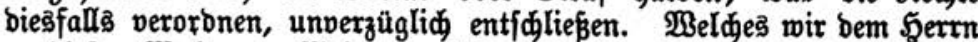
zu biefem $\mathfrak{R a l}$ guter Reinung nidjt enthalten mollen. $\mathrm{Ob}$ nun wohl,

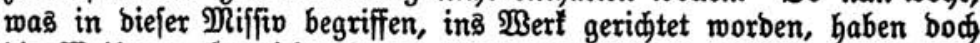
bie $\mathfrak{B}_{\text {Biber }}$ megr niđjt, benn wie oben betannt. Darauf biejes $\mathfrak{u} r=$ theil exfolget:

Ad eundem 31. Mai 1603 exfennt, baß́ bie Dorothee mit ihrem Berbreden verfdulbet, baß fie zur Staupen gefdlagen und bes Drta emigliden verwiefen, bie \$agnerin aber unb bie Diegrin 'mit annehgm= lider (sc. annehmbarex) Bürgfdaft, wenn unb zu weldyer Beit fie ex= forbert (sc. vorgelaben) werben, fid wieber zu geftellen, verfaffet und zu biefem $\mathfrak{M a l}$ ber gefängliden Sুaft und $\mathfrak{B e r w a h r n i s ~ e n t l e b i g t , ~ u n t e r ~}$

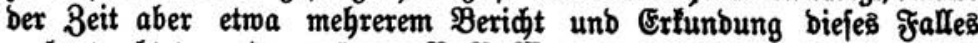
nadgetradtet werben möge. $\mathfrak{B}$. $\mathfrak{R}$. $\mathfrak{B}$.

Begrünbung: Non erant sufficientia indicia, ex quibus illae mulieres torturae subjicerentur. Ac etsi certo constare non poterst, 


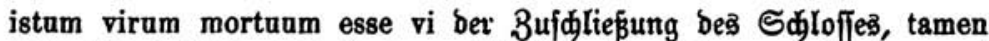
quia hoc factum esse ipsa ancilla fateretur et mors etiam sponsi secuta est, cujus nulla alia causa investigari poterat, tum etiam propter insignem illam levitatem et improbitatem ancillae, quae in templo fecit, conveniens visa est haec poena huic delicto.

श्रlo: weil fid feine anbre Tobesurjache ermitteln ließs, fonnte

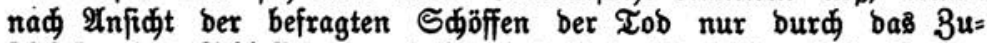

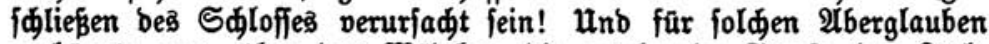

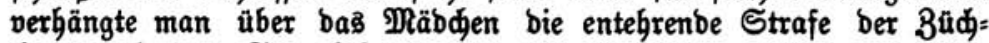
tigung mit bem Staupbejen!

Inngleid ftärfer als auf bem Bebiete ber Şexenverfolgung tritt

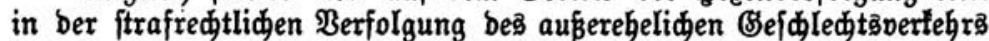
ber Einflußs ber bigotten Theologie auf bie ভtrafređtôpflege zu Tage.

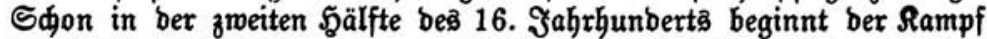

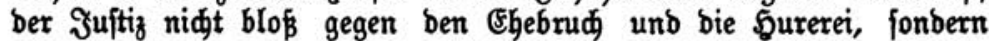

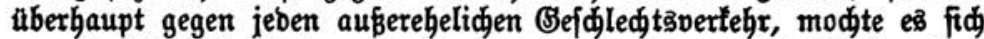
um cin Sonfubinat ober um irgend einen anbern gejwledtliden $\mathfrak{H} m=$ gang zwifden Unverheirateten hanbeln, uno mit einer Engherzigteit und Rigorofität wurbe biejer Rampf gegen bie "greuliđje" unzudt,

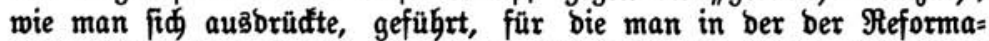
tion vorbergehenben 3 eit vergebens naw Beifpielen jubt. Sn jebem zur $\mathfrak{A n}_{\mathrm{n}}$ eige gelangenben Falle murben bie betreffenben \$erjonen ge= fänglid eingezogen und zur Strafe ausె ber Stabt verwiefen. Ram eș bod fogar vor, baß̧ man eine Dienftmagb, bie ausె bem Beifdlaf mit einem Reinmebergefellen fdumanger geworben war, trob̧om fie

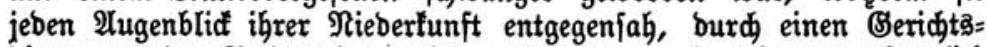

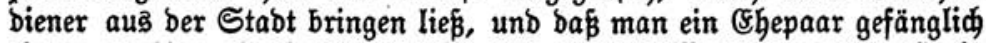

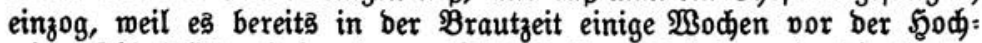
zeit gejdlechtlid miteinander verfehrt hatte. Dabei wurbe bie Unter=

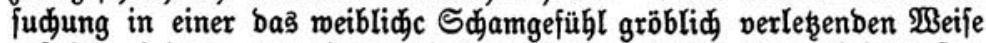
gefübrt, indem man bie zur א̧aft eingelieferten $\mathfrak{T a ̈ b d j e n ~ b e i m ~ e x f t e n ~}$ Berbör - weldeả nidt vor einer ridterliden ßerjon, vielmehr burd

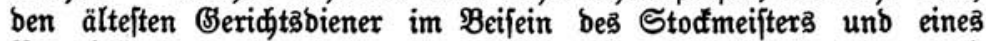
ßrotofolfführexs, beš fogenannten "Fragejđreiberä" erfolgte - regel= mäpig bie frage vorlegte: mit wem fie "Zeit ihreả Rebens" in Breả= lau obex anbermärts $\mathfrak{u}$ nzu山t getrieben hätten? Wie, wann, wo und

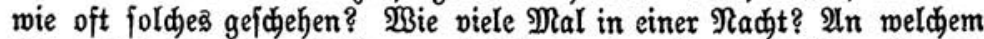
Drt und in weldher Stellung, ob ftehend ober liegend? Ber fie ent= jungfert habe? u[w. und ignen beim Seugnen ben Scharfridter unter

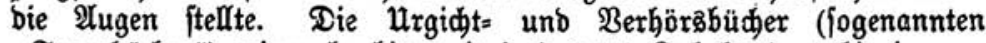

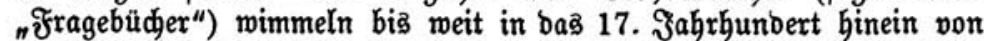
bergleiden Fällen. Nod im exiten ber brei Malefizbüder find bie Berweijungen von $\mathfrak{M a ̈ b d e n , ~ b i e ~ e i n ~ R i n o ~ g e b o r e n ~ o b e r ~ u ̈ b e r b a u p t ~ m i t ~}$ einem Panne gefdledtliden Utmgang gepflogen hatten, und nidbt we= niger ber $\mathfrak{R a ̈ n n e r ~ f e l b f t , ~ w e n n ~ f i e ~ f i ́ h ~ a m ~ D r t e ~ a u f b i e l t e n , ~ u ̈ b e r a u s ె ~}$ দäufig. $\mathfrak{A} u d$ gegen bie Dienftherridaften wurbe eingefdritten, wenn

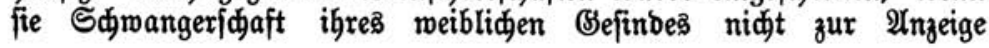


bradten. Später verlieren fī bie Straffälle, fei ę̧, baß̄ man bie

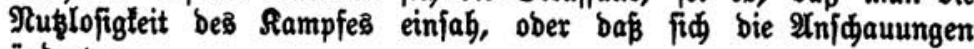
änberten.

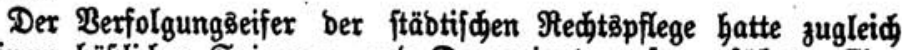
zu einem häßliden Spionage= und Denunziantenwejen gefübrt. Eine

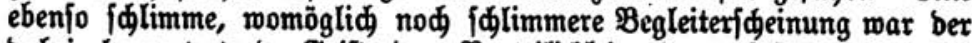
babei bcroortretende Beift ber \$arteilidłteit, benn faft burdgängig

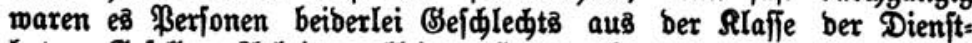
boten, Befellen, 2trbeiter, fleinen \$anowerfer und ber Töbter von folden, gegen bie man in fo rigorofer Beife vorging. Die böheren

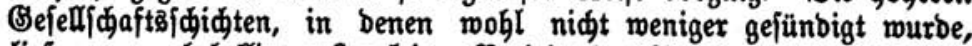

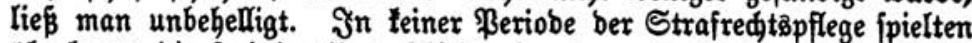

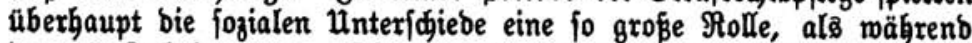

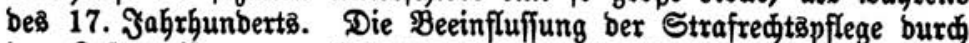
ben Raftengeift, namentlid bie fo viel glimpflidere Behanblung bes abeligen $\mathfrak{P i f f e t h a ̆ t e r s ~ b i l b e t ~ e i n ~ h e r v o r f t e d e n d e s ~ M e r f m a l ~ b i e f e r ~ B e i t . ~}$ Befannt ift bie ängftlide Sheu, mit ber man in allen Stanbes: flaffen ber törperliden Berührung mit bem Sđjarfridter und beffen

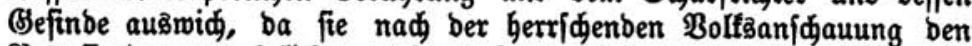
Betreffenben "unebrlid" madte. So mähtig war biefes Borurteil,

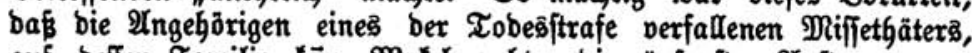

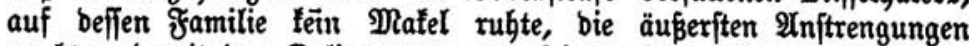
madten, bamit bem Delinquenten vor feinem leşten Bange bie Sুänbe nidit vom Sळarfridter, fonbern von einer unbejdoltenen ßerfon ge= bunben und aud jebe anbre Berührung zrifíden ihm und bem Delin= quenten vermieben mürbe. Uluळ bie Berurteilten felber baten bäufig um biefe க̌unft. Waả aber ben Beteiligten aủ ben untern Stänben nur auŝnahmb = und bittweife gemährt murbe ${ }^{3}$ ), geftand man bem Berbreder von 2lbel aus freien Stüđen zu, ja man war fogar mit peinlicher Sorgfalt bemüht, von ber \$rozebur alleà fernzubalten, was bas̄ Standeşbemuptfiein bes̉ Delinquenten uno feiner familie bätte verlez̧en fönnen. Der erfte Fall biefer SIrt batiert vom Jahre 1618. Der bamalige Borfiz̧ende des Sdjöffentollegiums gat ign mit aller $\mathfrak{U}$ mftänolidfeit in bas exfte ber brei Malefizbüder anbangsెmeije ein= firreiben Iaffen.

3) Die Dalefigbüd)er II und III, beicnders das exftere von beiben find

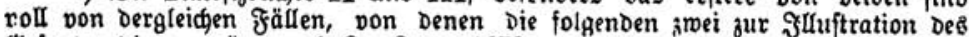

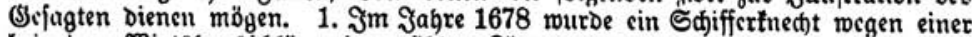

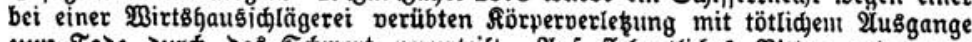
zum ToDe Durd Das Edjwert verurteilt. 2tuf flegentfides Pitten und nzum

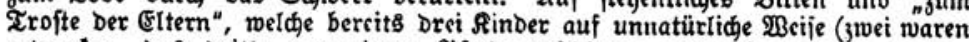
ertrunten, bas Dritte von cinem \$fferde erfiflagen roorden) verloren hatten,

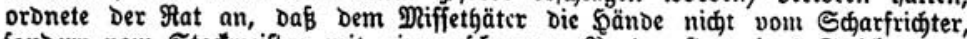

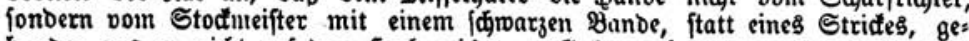

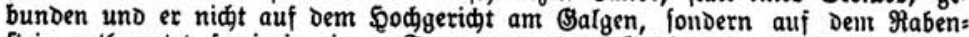
ftcin enthauptet, fomie in einem Sarge unter Dem Séteit von zmei ßerionen mit Sejang auf Dem friedhofe beerdigt merden folle. 2. Einer aut 6. Mlai 1700

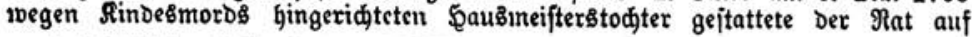

Bettístft f. b. gef. Strafredț̣̂m. XXIII. 


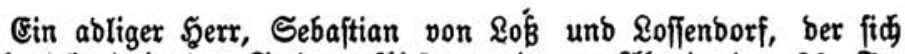
vortibergehend in ber Stabt aufbielt, wurbe am 2tbenbe bea 20 . Fुe= bruar 1618 auf bem Neumartt mit einem Standeşgenofien hanb= gemein und rannte bemfelben ben Degen burd ben Leib. Der

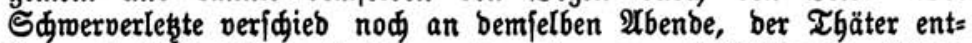
floh unb bielt fid verftedt, wurbe aber am nädfffolgenben Tage,

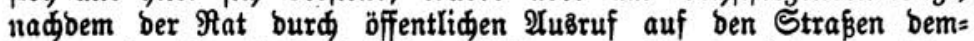
jenigen, ber ben 2Lufenthalt beßె Thäteraె zur 2Inzeige bringen mürbe, eine Belognung von 50 Brulben zugefichert hatte, ermittelt und zur Shaft gebradt. Pan legte ign aber nidt wie bie gewöbnliden $\mathfrak{B e r}=$

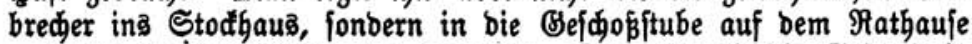
und ließs ign burd Solbaten bewaden. Da er burd fein SEeftänonis unb bie Zeugenauşagen bet That vouftänbig überführt war, mußste'

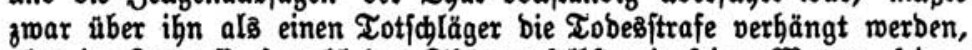

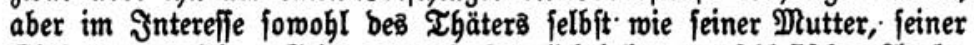

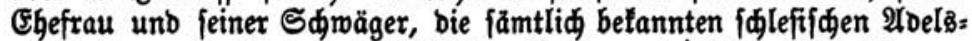

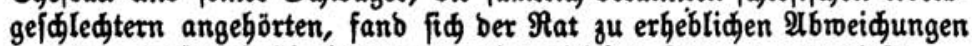

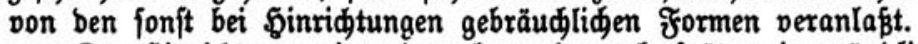

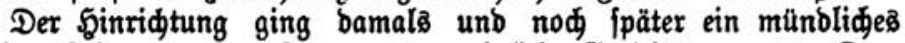
Sdeinverfahren - bas fogenannte "peinlide Sseridt" voraus. Dem 值belthäter murben im Stođłauje vom Sdarfridter bie Şänbe ge= bunben, barauf legte man ihm einen fdrmarzen Mantel, ben foge= nannten "Trübemantel", um, unb in biefem 2 uffuge trat er in $\mathfrak{B} e=$

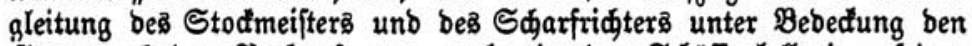

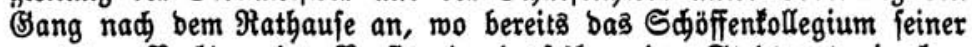
wartete. Radbem ber Borfiz̨enbe beşelben, ber Stabtoogt, in Ger= gebradjter \$eife bas Beridht gehegt, wurbe ber itbeltbäter vom Stod: meifter uno Sdjarfridter in ben (Beridtajaal (bie Sdjoffenftube) ges führt; ber Stodmeifter trug, an bie Sdgranfen treteno, bie Itntlage vor, uno wenn ber 2Ingeflagte bei feinem in ber $\mathfrak{U}$ nterfuchung abge=

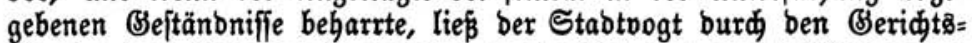

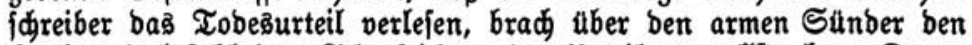
Stab uno befahl bem Sdarfridter, bas $\mathfrak{u}$ rteil zu volfftreffen. Daran

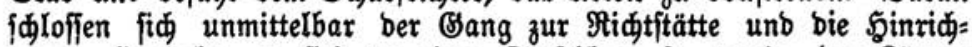
tung. Sanbelte es fich um einen Totfdlag, fo wurbe ber fiörper beä Enthaupteten nid̆t von bert Şenfers̆tnedten, fonbern von ben

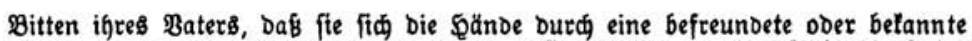
\$erfon mit einem fíwarzen Bande binden laffen Durfte, welden Siebesbienft ifgr

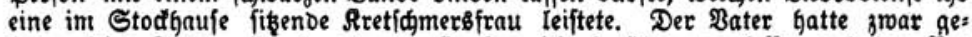

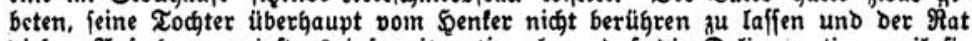
Diefem $\mathscr{A}$ nfuden wenigftens injomeit entiproden, Daß Die Delinquentin, weil fie Der Senter ohnedies fdon bei Der Tortur in Sänben gegabt, von ihm an einem "Striđel" auf Dem Sange zum Rabenftein gefübrt werden follte. Sie mar aber

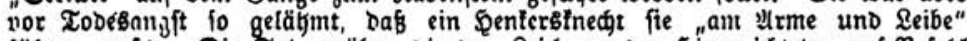

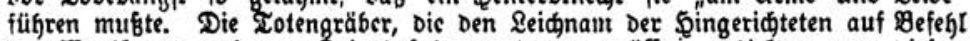
Des Magiftrats nad) Dem \&

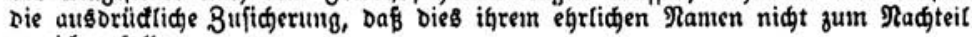
gereidjen folle. 
Totengräbern in einen bereitfteḩenben Sarg gelegt unb unter Beglei= tung zweier \$riefter unb ber EGorlnaben auf bem Rirdhofe beerbigt.

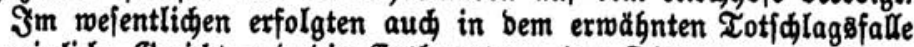

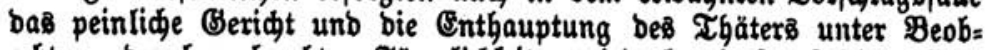
a dtung ber hergebradten förrmlidileiten, jebod mit forgfältiger Ber. meibung jeber aud nur inbirelten Beriłhrung bes Delinquenten bur

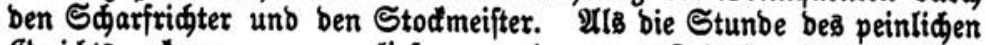
Beridts getommen war, ließ man bem von Soßs burd einen Reit=

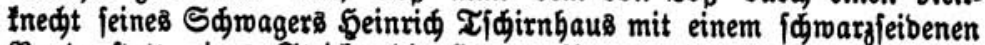
Banbe ftatt eines Strid's bie Sănbe binben, legte $i$ gm einen gang neuen, vom Sdarfridter nod nidt berulbrten Trubemantel um, fezzte igm einen grünen Pajorantrang aufs Saupt und füfte ifn in gleitung von zwei Raplänen unter militärifđer Bebeđung in bie

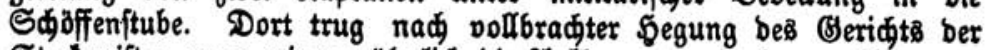
Stodmeifter gmar wie gewöhnli申 bie Antlage vor, bod war ifm vom

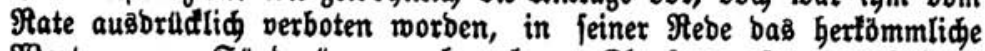
Bort "armer Sünber" zu gebrauden. Ebenio mujte ber Sळarf: ridter, in bejकeibener Entfernung auf ber Sdiwelle ber Sdöffenitube ftehenb, in ber Gertömmliden 2rntwortrebe auf ben an ihn ergangenen BoIftredungöbefehl fid ftatt bes ubliden \$ortes "armer Sünber"

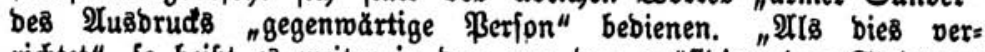
riळhtet", fo heift ę weiter in bem von bem präfibierenden Stabtvogt nadgegendos eigenhänbig verfaß̧ten Beriđd, "find Stodmeifter und

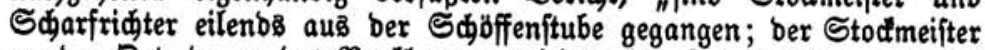
an ben Drt, ba ex bas \$rotllama verridtet, ber Śdarfridter aber fich unter bas $\mathfrak{B}_{0}$ If mit umgehabten Mantel unb ¡đwarzen Fुut verborgen

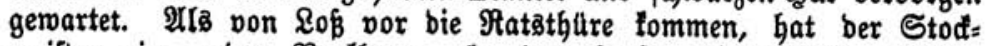

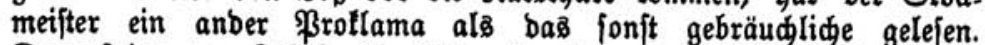

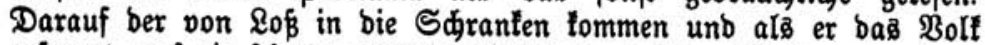
gefegnet, auf ein fdmarggemänben $\mathfrak{T} u \dot{\omega}$, fo auf bem Sanbe von einem S\$wertbiener aufgebreitet morben, niebergelnieet, ber Sdarfridter ihn mit einem Streid enthauptet und ift ber Sdarfridter, wie ihm bes fohlen worben, ftrats bavon gegangen mit feinem Bsefinbe, feine Saand

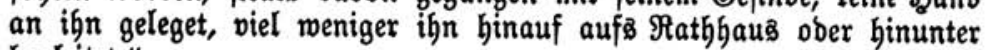
begleitet."

Die Reide murbe gegen bie fonftige B̧emohnheit nidit fofort auf ben Sirdhof, fonbern zunädjt von mehreren Totengräbcrn in bie

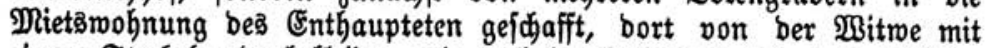
einem Sterbehembe betleibet und nad ber Befperzeit mit auß̧brüdlicher

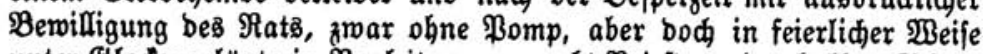
unter (Slodengeläute in Begleitung von adt ßrieftern, ber halben Sđule und einem ftattliden Reidengefolge auf bem Sirdhgofe zu St. Barbara an einer von bem Enthauptcten gefauften Stclle zur Rube bejtattet.

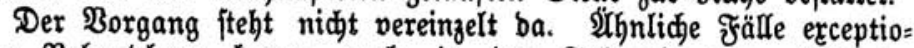
neller Bebanblung tamen aub in ber folgezeit vor. Nit be=

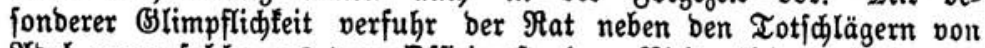

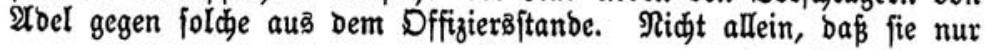


mit einem fdwarzen Banbe gebunben, zumeilen jogar ganz frei zur

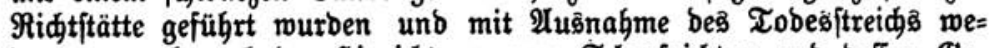
ber vor nod nad ber Şinridtung vom Ṡaarfridter und beffen Be= finbe berührt merben burften; aud igre Beerbigung gejdah unter $\mathfrak{B}_{e}=$ obadtung aller firdliden Zeremonieen in einem mit frifdem Brün ge= f́mmüđten, mit einem Reiđentud bebectten Sarge. In einem Falle

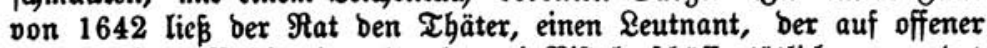

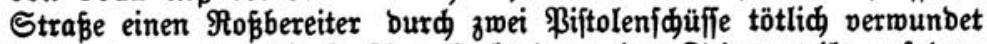
hatte, fogar ohne bie fonjtige Bertünoung besె Tobesెurteil’ auf bem

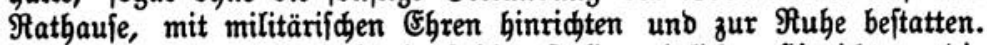

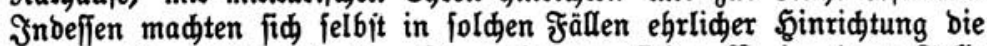
fozialen Borurteile geltenb. $\boldsymbol{C}_{0}$ meigerten fid $z . \mathfrak{B}$. in einem fralle von 1637 bie Totengräber, einen Şingeridteten aufzubinben uno in ben Sarg zu legen, obwogl er nur vom Stodmeifter mit einem fdwarzen Banbe gebunden worben war, fo baß ber $\Re a t$ biefen bamit beauftragen mujte. (Es fdeint bierna ben Stof́meifter megen feinesె häufigen gefđäftliđen Bertebra mit bem Sdarfridgter nod wie ein Jahrgunbert früher (vgl. Z X 7) für "un= ebrlid" angefehen. $\mathfrak{u}_{m}$ ber übeln Nađrebe vorzubeugen, liejen fid baher nidt felten bie Şinterbliebenen eines juftifizirten Malefifanten

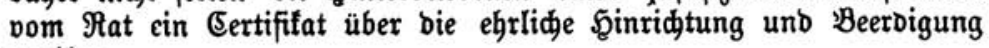
erteilen.

Bie menig ßarität bei fonjt gleiden Thatumitänben binfidutlid

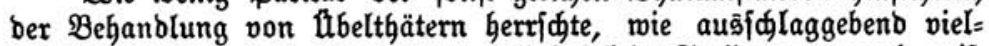
mehr in biefer Beziegang beren gejelffhaftlide Stellung war, bemeijt

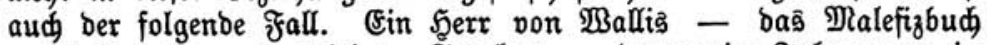
nennt ihn einen "berüdtigten Etänfer" - Der menige J̧ahre zuvor in Bres̄lau jemanden erftoden hatte, jebow vom Raifer begnabigt wor= ben war, hatte am 27. Februar 1678 in einem Bierbaufe, mofelbft jid faiferlide Berber befanben, nad "unterfdicoliden verübten İnjo: Lenzien" einen jungen Stubierenben aus̆ abligem Şauje mit entblößtem Degen an ber Şand gefäbrlid vermundet. Mit einem gemöhnliden îtbeltbäter hätte man unter ähnlidjen Berbältniffen menig Federlefens gemadt. Da aber beide Teile, ber Berleşte mie ber : Berlez̧er, auß vornebmem Szauje waren, fah fid ber Rat in einer fdpierigen \&age. Die Benugthuung für ben Berlę̧ten burfte niđ̆t zu gering ausfallen, anberieits̄ idjeint man aber aud ben libelthäter nidht wie einen ge=

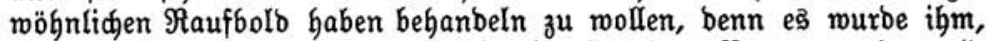

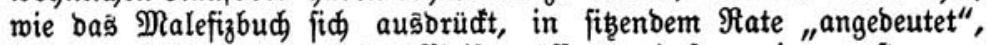

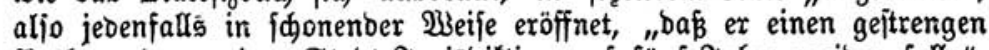

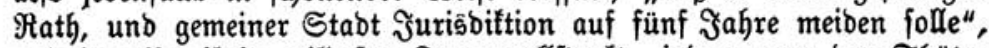
unb bas $\mathfrak{U}$ rteil in milbejter form volfitreft, indem man ben Thäter

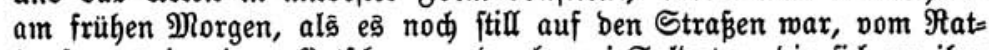
hauje aus̄ in cinem Siutidiragen burd zroei Solbaten, bie fid zu igm

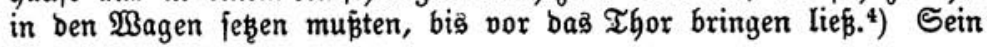

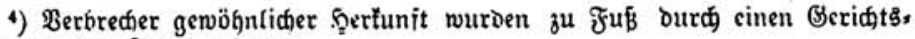
Diener aus Der Etaot gebract). 


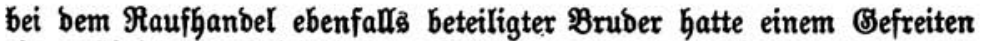
einen Şieb ober Stid in ben Ropf verfeşt, ba bie Berwunoung aber nur einen gemeinen Solbaten betraf, fam ber Thäter mit einem.

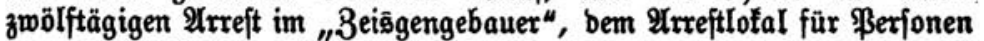
vornegmen Standeż auf bem Mathaufe, bavon.

In ben 131 Jabren von 1609 bis 1740 baben im ganzen 304

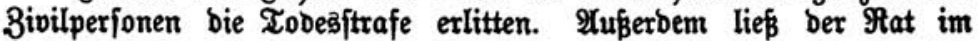
Jahre 1620 einen Transpport gattenber Solbaten - 27 an ber 3ahl - bie von Brieg eingeliefert waren, und in ben Jabren 1631 und 1634 zegn Prann ber von ber Stabt geworbenen Sölonertruppe megen હtraß̧enraubeả aufbängen. Bon ben Gingeridteten Bivilperfonen

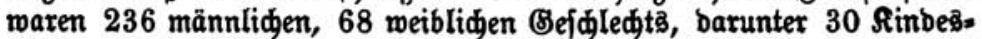
mörberinnen. Die Strafe wurbe vollftredt bei 30 burd ben Strang,

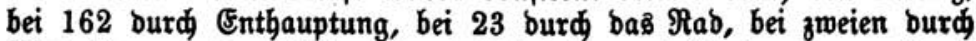
Bierteilen, an ben übrigen burळ̆ Ertränfen und Berbrennen naథ er= folgter Enthauptung. Die Strafe ber öffentlichen श्duß̈peitfidung an ber Staupfäule exlitten 338 Snbivibuen, 213 männlide unb 125 meiblide. Unter preupifder Şerridaft verringerte fíd bie Berbängung von Rebens= und Reibes̄ftrafen fehr bebeutent. Wäbreno in bem Des zennium von 1731 bis 1740 nod 10 \$erfonen bingeridtet worben maren, fanden in ben nädiffolgenben zmanzig Jabren nur nod 9 Şin= ridftungen ftatt. Ulnter biejen 9 Singeridteten enbeten 2 Mäbden am BaIgen, was in ber Bres̆lauer \$raris früber niemals vorge= tommen war, weil baș 2 ufbängen von Frauensperfonen nad altex

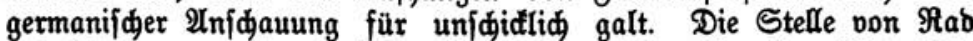
und Balgen vertrat von jeher, aud nod nad ber Carolina (2Irt. 130, $131,162)$, bas lebendig Begraben, \$fäblen und Ertränfen, an beren

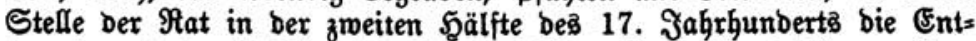

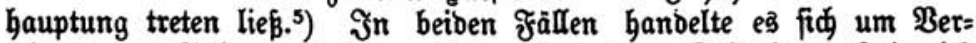
leitung von Solbaten bes̄ preusifiden Şeereș zur Defertion. Friebrid ber Brope hatte ein Mandat exlaffen, wonad biejenigen "Weibşbilber", bie einen feiner Soldaten zur Defertion verleiten mürben, "fonder

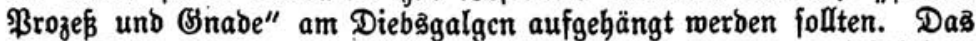
erfte Opfer biefes Strafbefeh̆

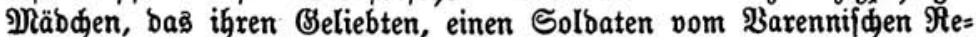

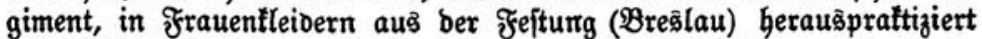
und fid mit ihm nad Militjd gemanot hatte, wofelbjt man bie flüd)=

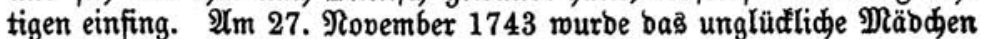

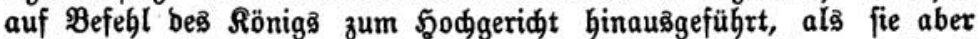

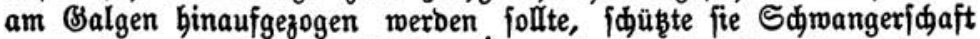

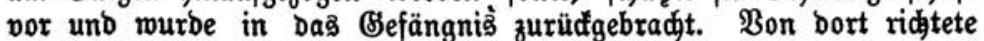
fie ein Bnabengefuch an ben Rönig, aber ogne Erfolg, und ba fid jener Bormand, zu bem ibr bie jefuitifden Beidtzäter geraten haben follten, alą unrid̆tig herauŝftellte, wurḅe fie am 19. Dezember besె= felben Jabresె am Diebägalgen gebängt.

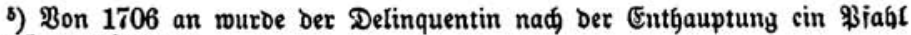

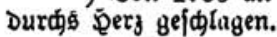


Die zmeite Delinquentin hatte einen Solbaten vom :Blanfenfee= füen Regiment zur Dejertion verleitet und wollte mit ibm über bie Brenze flüdten, wurbe aber fdon am Tage nad ber Entweidung (25. Pai 1751) famt ihrem Bjeliebten aufgegriffen und nad Brešlau zurüdgebradt. $\mathfrak{B a s}$ mit bem Solbaten gejळah, ift aus bem Dlalefiz=

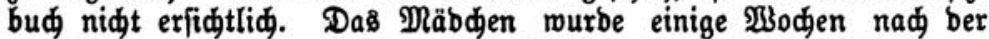
Berhaftung auf bem 5odgeridit mit bem Strange vom Leben zum Tobe gebradt und ber Rörper abenbs unter bent SSalgen ver[darrt.

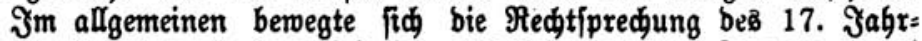
Gunberts in ben von ber ßeinliden Beridtsorbnung Sarl V. vorge= zeidneten Breleifen, und too fie anbre \$fabe einfdlägt, gejdiegt es nidt, um bie Şärten ber Carolina zu milbern, vielmehr äukert fich in ben meiften Neuerungen eine mandmal bis zum Ertrem gejteigerte

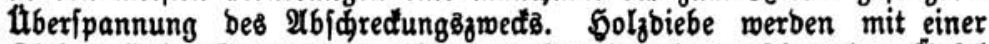
Rlafter 5ुoly, Bartenbiebe mit einer Barnitur ber gejdüttelten Silpfel und Birnen um ben 5ुals an ben Branger geftellt. Ein Betrüger muß̄ Sumpen, Sieş unb Biegelf́tüde, bie er in verfiegelten Siäftchen

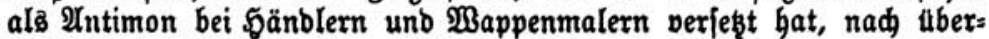

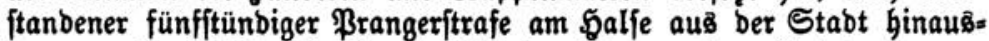

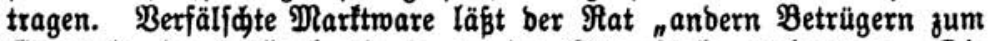
Erempel" burd Sgentersెhanb an ber Staupfäule verbrennen. Die

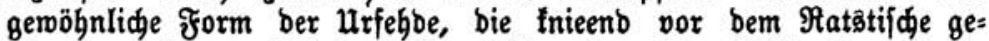

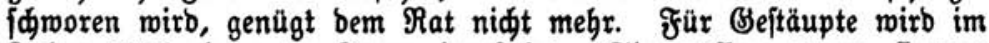
Jahre 1626 eine neue frorm eingeführt. Sie müffen, menn fie vor bem Thore vom Sdarfriđter loĝgebunben finb, bie $\mathfrak{u} r$ fehbe auf beffen

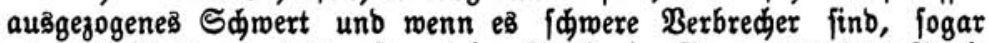

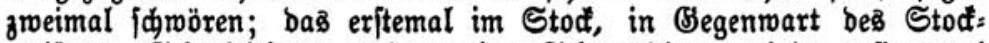
meifterŝ, Sđarfridters und zweier Sdpertbiener, inbem fie zmei

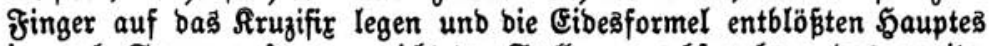
in nad Sonnenaufgang geridteter Stellung nadipreden; bas zroeite: mal in berfelben Stellung vor bem Thore auf bas auşgezogene

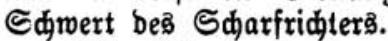

Ber fid eingehenber mit ber Befamtreihe ber Breălauer VRalefiz=

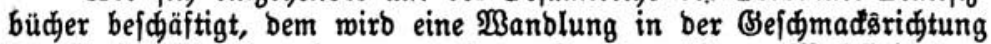

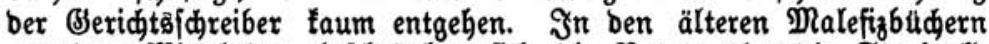
ausa bem Mittelalter befdränfen fí bie Notate über bie Strafvoll=

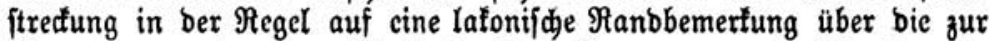
Unmenbung gefommene Strafart, alą $\nsucceq$. B. suspensus (gebängt), rota pressus (geräbert), submersa (ertränft), viva sepultu (lebenbig begraben), gladio, fune judicutus (mit bem Sdpert, mit bem Strange geridtet), "mit ber Weibe geridtet", b. h. mittela ciner Sdjlinge aus ruten an einem veroorrten Baum aufgehängt, fustigatus (mit bem

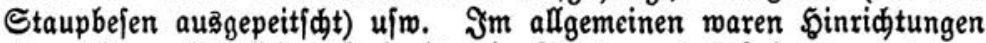

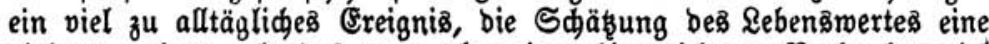
viel zu geringe, als baß man über einen hingeridteten Berbred)er vicl Worte bätte verlieren follen. Nur wenn fid bei ber Strafpoll. ftreffung ganz ungewöhnliche $\mathfrak{U}$ m $\{$ tänbe ereigneten, wenn aljo z. $\mathscr{B}$. zum 
Maffertobe verurteilte Frauenæiperjonen niđt unterjanten, fonbern vom Waffer lebenb ans $\mathfrak{u f e r}$ getragen wurben, wurbe ber $\mathfrak{B}$ orfall als ein

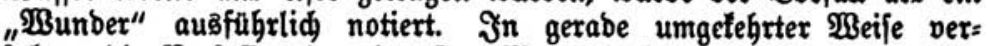
fubren bie Berfaffer ber jüngften Malefizbüder. Bei ber Strafthat felber balten fie fid nidyt lange auf, fie begnügen fid in biefer $\mathfrak{B} \mathfrak{c}=$

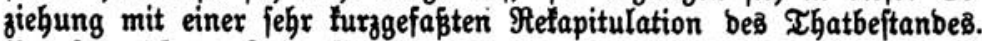
$\mathfrak{u m}$ fo größereả Sntereffe inebmen fie an ber Strafoolftredung mit allen igren Rebenumftänben unb an ben lesten 2lugenbliden ber armen

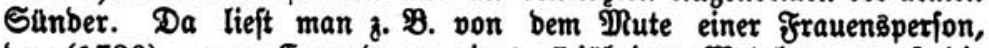
ber (1729) megen Ermorbung eineả 7 jäbrigen Mäbdensె zuerft bie 5and und bann ber Sopf abgefdlagen wurbe: "fie mar fehr grof von ßerfon, now größer aber war ihr Beift unb igre Stanbhaftigs feit, womit fie bem Iobe getroft hergehalten", und anberfeiţె über bie Baghaftigfeit von vier Bigeunern, welde wegen veridiebener $\mathfrak{B}$ er.

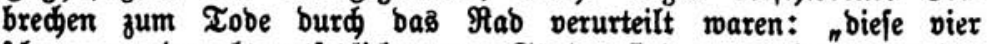

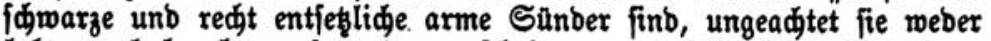
lahm nod frant gewejen, ber gefdehenen unterfidedliden Ermabnen zuwiber fo hartnätig gemejen, Daß̧ fie mit ibrem langfamen Bange aus bem Stodthaus bis zum Ratbhaus mehr als eine Stunde und von ba bis zum \$odgeridit (vor bem Sdjweibniper Thore) bis in bie britte Stunbe zugebradt." Pit berfelben BSenauigteit, wie über baş Berhalten jebes armen Sünberoె vor und bei ber Sinridatung, wirb bei

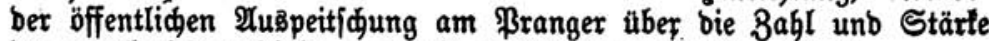
ber verabreidten Şiebe, und wie ber Delinquent fid babei benommen,

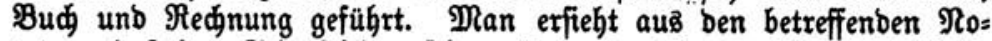
taten, baß̧ ber Sdarfridter feinen $\mathfrak{B}$ ejen in febr verfdicbener $\mathfrak{B}$ eife Ganbhabte, benn ber Slimar fteigt von "mäpigen" zu "guten, ftarten, gar guten, fegr barten und guten und überaus ftarfen" Şieben. Die eine Frauensperfon hat bie 30 "guten" Streide "auf ihren fetten

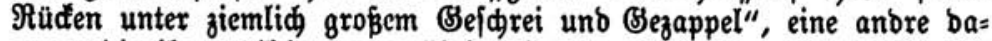
gegen bie ihr zubiftierten 18 Sूiebe "herzhaft ohne Buden und Pudten" unb eine britte igre 36 "ohne bie geringfte Berwegung wie ein Stod" auşgeftanden.

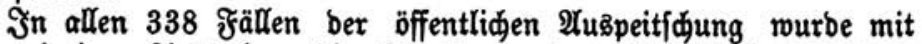
einer eingigen 2Uus̄nabme bie Strafe an ber Staupfäule vor bem

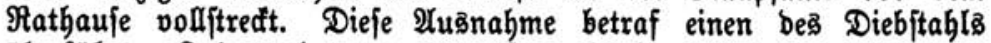
ùberfühtten Şuben, ber von ber Staupfäule aủ unter abją̧weifen Staupenfdlägen bis voră Thor getrieben und bort nad geleifteter $\mathfrak{u}$ rfegbe verwiefen murbe (25. 2lpril 1697). Einen Dieb drriftlider Sonfeffiton mürbe man in gleidem fralle einfach an ber Staupfäule

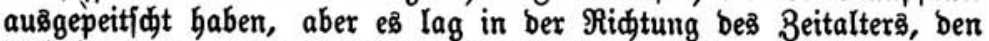
jübifiden $\mathfrak{B}$ erbredjer idimpflider zu behanbeln, alä ben driftlidjen. So

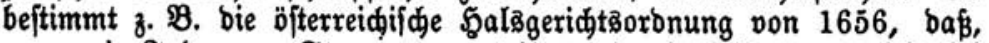
wenn ein Şube zum Strange verurteilt merbe, Derfelbe zmar nidft bei

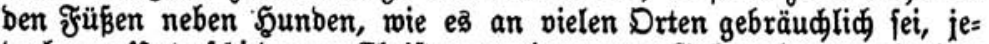

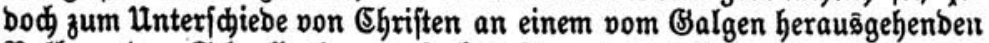
Balfen ober Sdgnellgalgen aufgeftüpft merben folle, uno nod in ber 
Rriminalorbnung ber Raiferin Maria Therefia gilt ber $\mathfrak{U} m$ mftanb, baß̄

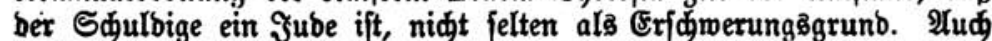

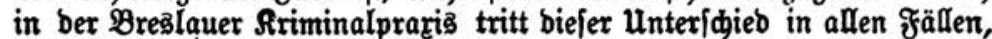

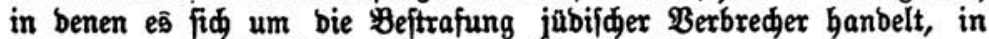

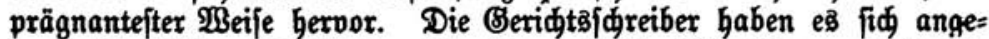

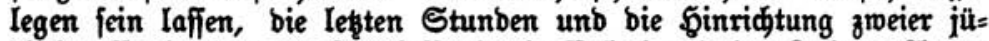

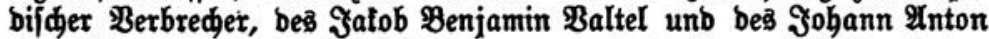
Leopolb, von benen ber exitere wegen eines ibjm zur \&aft gelegten

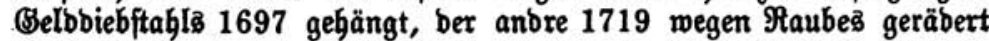
wurbe, wegen ber babei von jefuitifder Seite entfalteten \$rojelytens maderei mit befonberer 2Ausfuhbrlidffeit zu fuilbern. Der Seelen= rettungäeifer ber J̧efuiten und ber beharrlide \$Biberftand ber Delin=

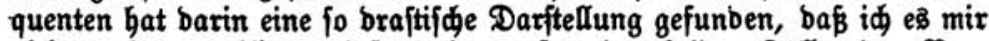
nidst verjagen will, menigitens ben exften ber beiben fälle, ben $\mathscr{P}$ ens jamin Baltel betreffend, im Bortlaut herzulez̧en. "Diefer verzmeifelte, vermalebeite Sube", fo lautet bie Stelle, "welcher bem Rathgaufe

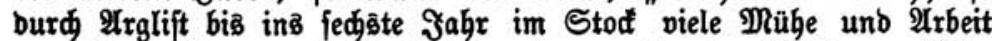
gemadt, nadbem ex anfänglid von ber zuerfannten Tortur an Ş̧re Raijerlidge Tajeftät appelliret, zulę̧̨t aber bie Raijerlidje B̈nabe ober gratiam Caesaream amplettiret, waro bennod vermöge eines̉ Raifer= liden Urtheils vor bem Sdweibnizer Thor am bohen Beridt auf bem oberften Balfen gebentet. Es ift in Den Rirden, wie fonft bei

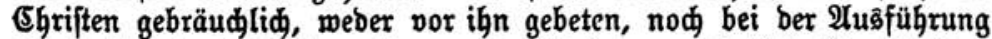

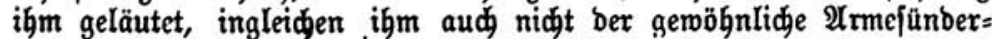
PRantel, fonbern ftatt befien ein anber zeugen Sleib, fo igm bie Şuben maden laffen, angeleget und babei befohlen worben, baß fein J̧ube

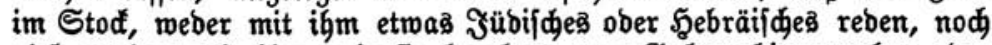
viel weniger mit $i \not h m$, wie fie begebret, zum Balgen binausgehen ober

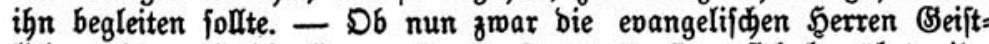
liđjen als aud bie Fुerren Patres Societatis Jesu fid bemühhet, ibn zum Ehriftenglauben zu bringen, fo hat er bod biejelben nidit gar

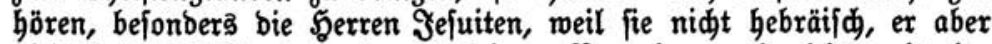
nidt lateinifi fönnte uno aljo feinem Borgeben nađ nidtä mit ein= anber madjen würben, bas nidt leiben wollen, fonbern biefe mit un=

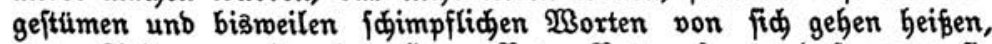
unter Anderem wiber ben Sgerrn \$ater \$ott gefaget: baß wenn fie fđ̆on wohin fämen, man ihrer niđgt losెwerben fönnte, fie wären wie ßed, wenn man eả einmal in eine hölzerne Ranne gieß̉e, fönnte man ez nidyt wieber herausbringen. Item, ein gemajdener $\mathfrak{B e l}_{z}$, jahmer $\mathfrak{B O}_{0}$ If und getaufter Jube wären alle brei nidłta nub̧e, benn ber ge=

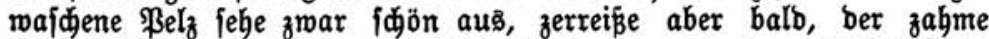
Bolf näbme aud feine wilbe $\mathfrak{A}$ rt wieber an, uno ein getaufter Jube

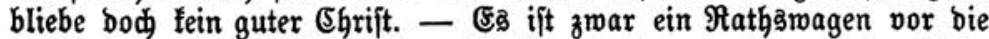
Serren evangelifiden Bei|tliden bejtellt gemejen, baß menn ber Jube bie Fुerren ßatreas etwa nidht leiben, fonbern auf alle Fälle bie $\mathfrak{u} n j=$ rigen verlangen wollte, fie binausfabren und bargegen bemfelben vor= ipredjen follten; meil aber P. ßott nebjt einem andern Jefuiten mit 


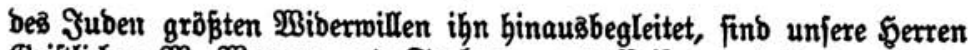
Beiftliden $\mathfrak{D}$. Werner und Teubner, auBె Beiforge, baß jene \&eute

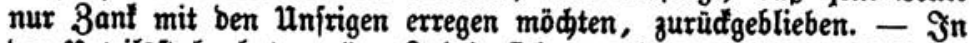

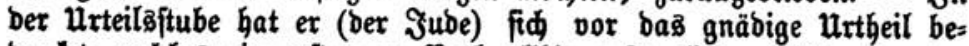

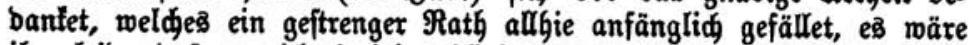
igm leib, baß̧ er nidt babei geblieben, fondern fid burd böfe Leute verleiten Iaffen unb bavon appellitt unb müffe bennod fterben; zu= gleid aud gebeten: 1. baß fein Beib und Sinber nidt verjaget; 2. bem Jubengejdledt feinethalben nidit fo viel Sdmad unb Spott vor ben Reuten angethan, und 3 . Den 5errn Patribus gefagt werben mödte, baj fie ign in frieben laffen follten, weil ex als Jube leben und fterben wolle, benn fie ftörten ihn nur in feinen \&ebeten. bat aud im 5ुinausigehen, ba fie igm ferner zugerebet, geidrieen, fie follten ibn in Srieben laffen, fonft würben fie fid nur Sdanoflede bolen. Den ganzen $\mathfrak{B}_{e g}$ in ber şinauşführung hat ex jübifळ gejungen, als aber auf bem S్dodgeridt ber eine Şefuit vor inm niebergetnieet uno Bott um bie Barmberzigfeit, baß̧ er ben Şuben erleudten wolle, an= gerufen, hat ber Sube mit verzerrtem Befidt und 3ufammenbeifung ber 3 äbne fíd umgerwendet uno ift endlid unter wieberboltem Be=

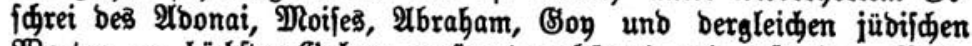
Borten am hödften Balgen gepögert (gehängt) und geftorben. Rad= bem ex eine fleine Breile gehenfet, hat Der Şenfer ihm bas Räpple, weil es ber Şube bei Rebzeiten eifrig begehret, auf ben Ropf ange= nagelt. Diefes alles ijt gefdeben ben 2. Martii An. 1697." Der Sabaver bes Baltel muß̄ jebenfalls jahrelang an ber Stelle gehangen Gaben, bevor er herunterfiel, benn nad einer fpäteren Rotiz vom 4. Februar 1700 wurbe an biejem Tage ein anbrer Jube "in feitrer

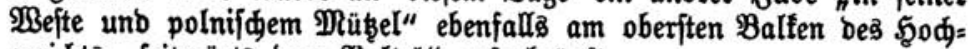

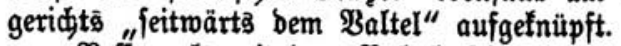

Beffer als mit bem Baltel fकien eả ben Jefuiten anfangå mit bem Juben \&eopold zu glüđfen. Sie hatten ihm ફুoffnung gemadit,

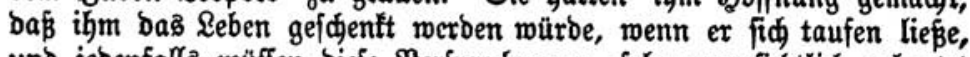
und jebenfallas müffen bieje Berfpreçungen fehr zuverfidtlic gelautet

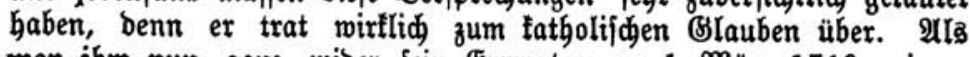
man ihm nun ganz wiber fein Erwarten am 1 . März 1719 , einem Pittwod, verfünbigte, $b a \bar{\beta}$ er am nädfiffolgenden Sonnabeno binge= ridtet werben mürbe, ließ er fid zmar im exften Sdgreden von ben

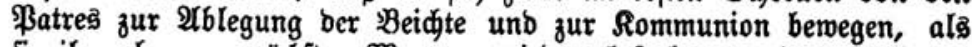
fie ibn aber am näbjten Dorgen wieber bejudten, wies er fie $a b$ unb erflärte ihnen, ex ftürbe alą ein Şube, benn fie hätten ihm baß ¿eben verfproden, igr Berfpreden aber nidjt gebalten, und bei biefer Erfflärung blieb er troß̧ aller Begenvorftellungen ber ßatreß̊ ftehen.

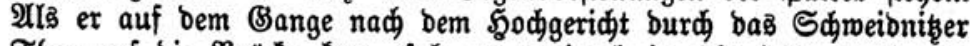
Thor auf bie Brüde fam, fah ex zmeimal in bie Fुöhe nad bem Worte Jehova, weldes über bem Stabtthor in Stein gehauen war, und fragte bie \$atres, ob fie cả aud lefen fönnten unb verftünden,

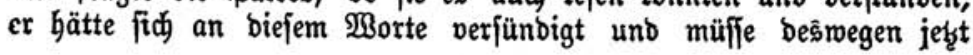


eines fđamähliden Tobes fterben. "Wie ex nun" - fo lautet ber

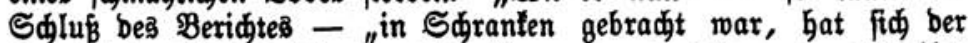
Serr ßater Eollert fegr bemüht, ighn zu perfuabiren, ja vor igm niebergefniet unb zugerufen: "Reopold (biefen Namen hatte man bem

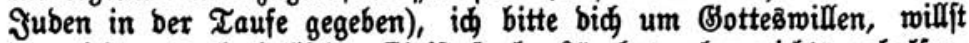
bu nidt alo tatbolifider Egrift fterben?" hat aber nidts geholfen, fonbern ben Sopf gefifuttelt unb gefagt: fie follten ihn ungeirret

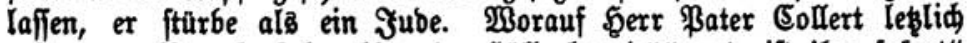

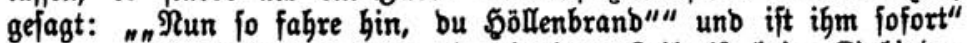
..... Gier bridt ber Tert ab, bie leşte Beile ift beim Einbinden

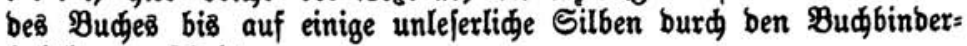
bobel weggejळnitter.

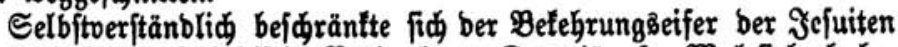

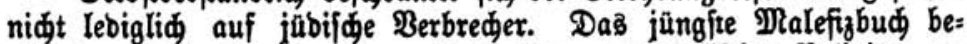
riditet zugleid ûber zwei an Berbredjern evangelifder Religion ge=

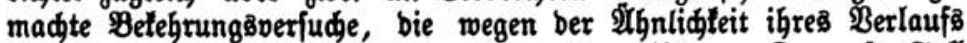
gewiffermajen ein Seitenftüd zu ben vorigen bilben. Der exjte frall betrifft eine frauenßెperion, welde (1720) wegen Diebjtablo und Brud̄s ber urfchbe bingeridtet werben follte. Da fie zmangsimeife

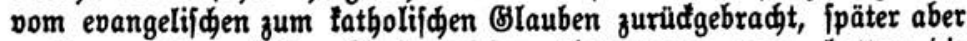
zu igrer uriprüngliden Sirde wieber übergetreten war, hatten bie Jejuiten beim Rönigl. Dberamt bie Siftierung ber Erefution burd, gejept, um fie wieber zum fatgolifden Blauben zurüdzubringen. Sie mar aber bierzu nidt nur nidg zu berwegen gewejen, fonbern ver= Iangte fogar ihre Sinridtung, "mafen fie ben verbienten und ifr zu= gefprodenen $\mathfrak{T}_{0 b}$ gern leiben, und feinesెmegs um igr Reben gebeten haben molle", nur folle man fie in ihrem angeftammten Blauben fterben Iaffen. Bezügliđ beßె weiteren Berlaufß̧ ber 21ngelegenbeit

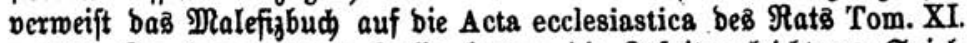
p. 85. In bem andern fralle hatten bie Jefuiten leidteres Spiel. Delinquent, ein ફुollänber von Beburt und reformierten Blaubens, welder ber Şehlerei und Teilnabme an einem gropen \$oftbiebjtable bezidtigt war, hatte fid fofort nad feiner Berhaftung erboten, zum fatholifiden Blauben übergutreten. Die Sefuiten erlebten aber wenig Greube an bem Ronvertiten, "maßsen ex mäbreno ber IInterweijung

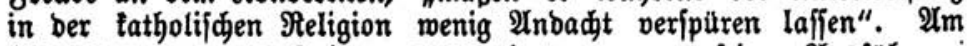

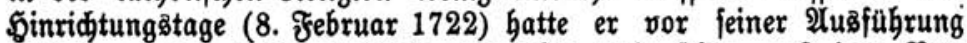
aus bem Stod 4 Quart $\mathfrak{B e i n}$ getrunfen uno fijon auf bem $\Re$ tat= haufe vor Taumeln taum mehr ftehen tönnen, trob̧bem trant ex auf

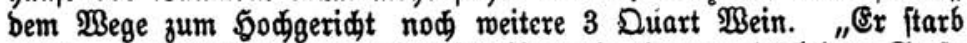

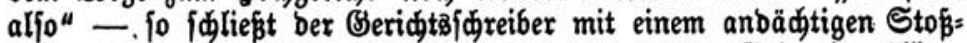
feufzer feinen Beridt - "ohne alle Bubereitung und Bebet in völiger

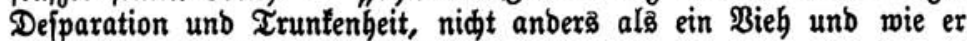
gefahren fei, ift Bsott belannt".

Fins ber widtigften und intereffanteften Dofumente finb bie 2 Uuf= zeidnnungen beş erften Malefizbudes über bie von ber Stabt geübte

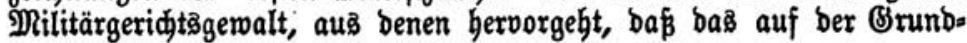




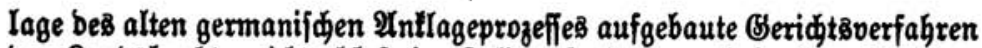
ber \&anosinedite nidt bloß im Gelbe, fonbern aud in ben Stäbten, welde Sölbnertruppen unterbielten, geübt wutrbe unb baß̧ biesె nod

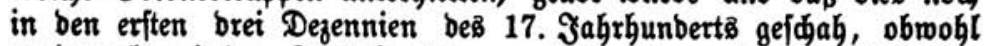

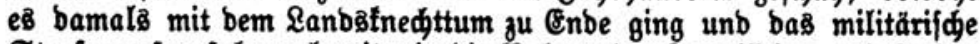
Strafprozepverfabren bereits in bie Babnen ber Snquifition unb folter einlentte.

Die Stabt unterbielt in ben 1620 er Jahren neben einer zabl= reiden wohlbewaffneten Bürgerwebr eine ca. 300 Mann ftarle Sölb= nertruppe, bie fogenannte "Stabt=ङuarbia", bie in Friebenszzeiten bie Bewađung bet $\mathfrak{W a ̈ l l e}$ unb Thore beforgte unb in Siriegşzeiten mit ber bewaffneten $\mathscr{P}$ ürgerfdaft zu folbe zog. Die Truppe beftanb aus zrvei fäbnlein und war lanbo̊lnedtartig organifiert. Sie unterftand

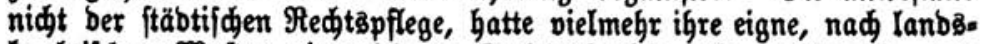

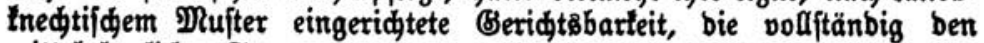
mittelalterliden frormen entiprad, wie fie Der Raiferlide gelbidultheiß \&ienbarbt frönspperger ( +1575 zu $\mathrm{Mlm})$ im Eingange feines brei-

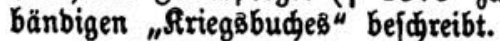

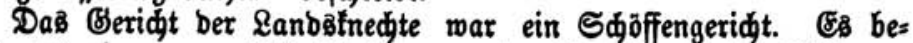
ftanb aus einem zum Sdultbeiß ernannten Sauptmann ber Sölbner=

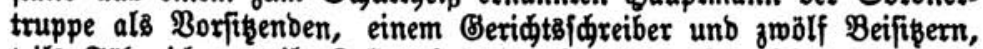

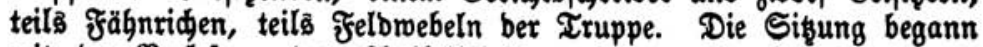
mit ber Berlefung beş Urtifelbriefß, auf ben bie Rriegsleute ge= fdimoren hatten. Darauf folgte bie Bereibigung ber Beifiłer und

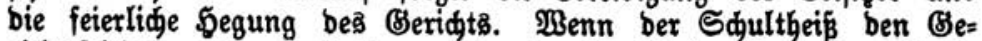
ridgtsfrieben gebannt hatte, wurbe in bie Berbanblung ber Sadje eingetreten. Der ßrofos ließ ben Befangenen vorführen, unb exbat fid einen Ffüripreder aus ber 3 abl ber Beifizer, burd, ben er ben Thatbeftanb ber Antlage vortragen und um Berlejung ber Rriegsiartifel, gegen bie fid ber 2 Ingeflagte vergangen hatte, bitten ließ̧. Ȩierauf

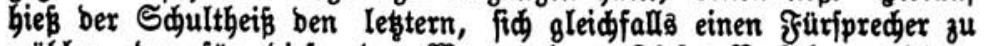
wäblen, ber für biejen bas Bort nabm. Diefes Berfabren wieber=

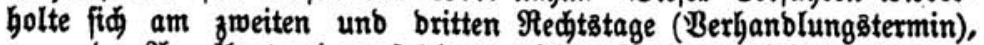

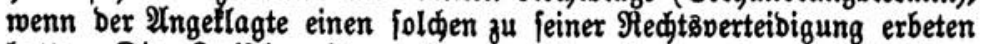
hatte. Die Brwifdenzeit wurbe zur Bernehmung ber beiberfeitigen Beugen und etwaiger fonftiger Bemeife beniust $t^{\circ}$ ), benn ber britte

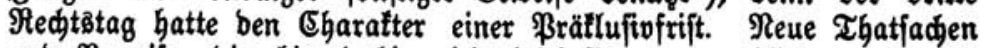
und Berveife, bie bia babin nidjt bejhafft waren, blieben unberild"=

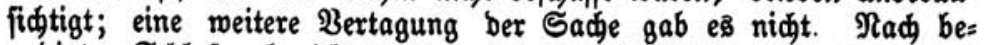

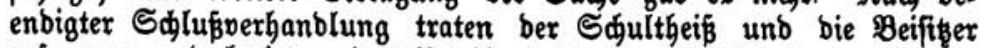
zujammen unb berieten bas Utrteil, baş vom Sdjultheiß im \$eifein beß̊ 2 ngetlagten publiziert murbe.

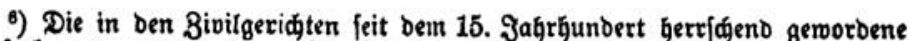

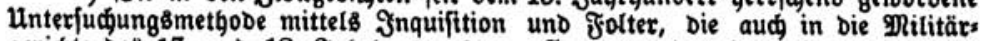
geridgte bes 17. und 18. Jagrbunderts verpflangt tourbe, hatte in Das Eseridt Der Sandötnchte teinen Êngang gefunden. Das urteil rourbe nur aus freis svilligem Beftänonis und beeidigten Zeugenausjagen gefiböpft. 
Frönsaperget teilt zmei $\mathfrak{u}$ rteils̄formeln mit, von benen folgende bie gebräuळlidere gemejen zu fein fđeint:

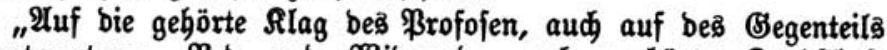

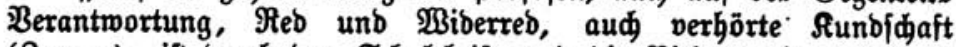
(3eugen), ift burd ben Sđultbeiß und bie Ridter mit einhelliger

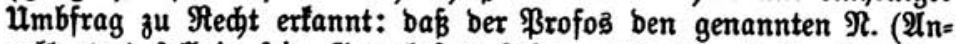
geflagten) foll in fein Berwabrfam fübren und fo er's begehrt, igm einen \$riefter zuoronen, baß ex feine Sünbe betenne und burd ihn zu emiger Seligteit gewiejen und getrôftet werbe. Dann foll ihn

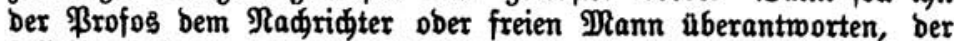
foll ign fübren auf ben freien \$laks, ba am meiften $\mathfrak{B}$ olt bei ein= anber $i$ it, und $i$ mm feinen Reib mit bem Sdmert entzweijdlagen, baß̧ ber Leib bas̄ größere unb ber Ropf baā fleinere Teil fei.

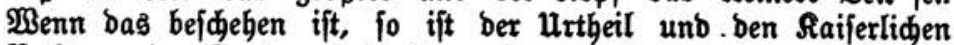
Redten ein Benüge gefळehen. Rann ex aber Barmbergigteit (Bnabe) exlangen, bas foll igm vorbegalten fein."

Şierauf brad ber Sdjultheip ben Stab entzmei und fprad: "Bott begleite bie Seel", ober "Bnab Bott ber armen Seel und

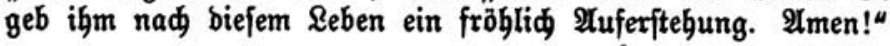

Benau in benfelben frormen berwegte fid ber \$rozeß gegen zmei Solbaten ber von ber Stabt geworbenen Sölonertruppe, bie (1621) wegen ¡ळmerer Bergehen gegen bie Rriegäbiazziplin militärgeridtlid zum Tobe verurteilt waren.

\section{Man vergleide:}

"Şeute dato ben 23. Şuni $1621^{\prime \prime}$ - fo lautet mörtlid bie

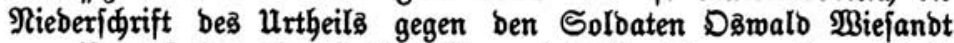
- „ift auf bie eingebradite Slage beș \$rofofen, aud auf brei aus̄gejagte Beugenidaften in Eibeşftatt uno auf bie mit Eibeŝftatt

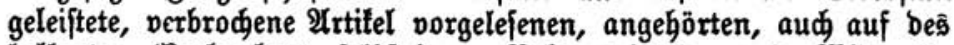
betlagten Berbreders felbfteigene Pefenntnišrebe und ßiberrebe

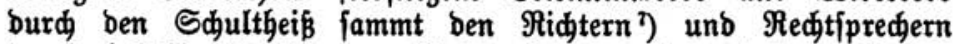

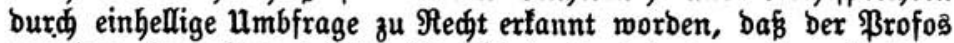

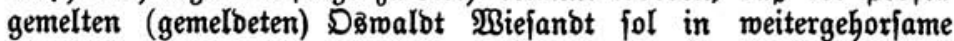
5anbveftung neל̆men und in Berwahrung führen Iaffen, aud aljo= bald ein(en) Beidtwater zu ihm fommen laffen, bamit er feine Sünbe gegen Bott ben थllmedtigen befenne, Reue uno Reib bar= über habe und bas hodmürbige. Saframent zu Begülf feiner Seele Das̄ Emige Reben zu exlangen, begehren, fo fol eả ihm gereidyt

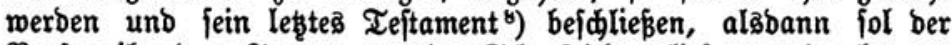
\$rofos ihn bem Fregmanne ober Sajarfridter liefern und überant= worten, ber fol ihn fübren auf freien \$lał und igm fein Reib in

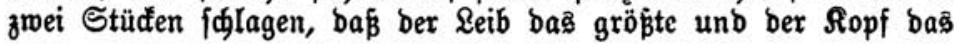

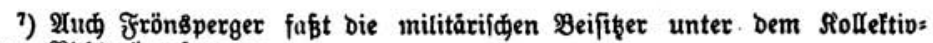

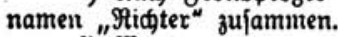

8) Worte aนธి Der zroiten in Frönsిperger mitgeteilten formel. 
fleinfte fei, alabban fol ex begraben werben wie in Rriegsijurişbit= tionen gebräudliden ift. Wsann foldes gejdiehet, fo ift bem Raiferliden Sriegäredtt ein Snügen gejdehen, auf heute biejen Iag. Эebod ber hohen Dbrigfeit igre Bnabe zu vorbehalten."

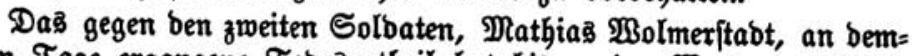
felben Tage ergangene Tobesెurtheil hat bis zu ben Borten: ${ }_{\text {nalsban }}$ fol ber \$rofos ihn bem greymann ober Sdarfridter liefern und überantworten", genau benjelben Bortlaut. Da aber ber Delinquent zum Tobe burd ben Strang verurteilt war, heipt es entipredend ber

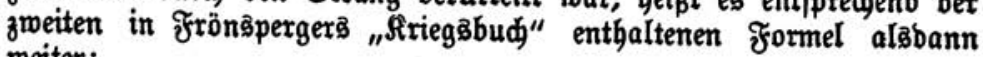
meiter:

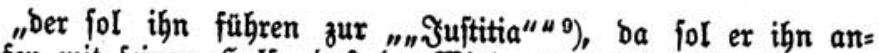
fnüpfen mit feinem bुalfe, baß ber fammenfillage, aud fol ign bie Sonne einen Tag anfweinen, als= ban fol ex wieber abgenommen und begraben werben" u|w.

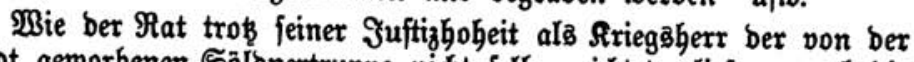
Stabt gerworbenen Sölbnertruppe nidt felber ridtete, ließ

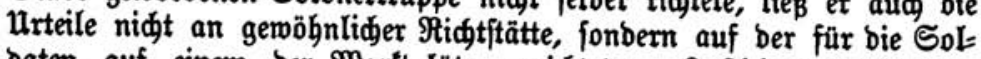
baten auf einem ber Plarttpläß̧e exridteten "J̛uftitia" volfftreden. So forberte es bie alte Ranbs̊nedtfitte. Denn fein Sriegsimann follte am gemeinen Sুodgeridte, fonbern am Baume ober Duartier= galgen hingeridtet werben, ber in ben Stäbten für bie Solbateåla

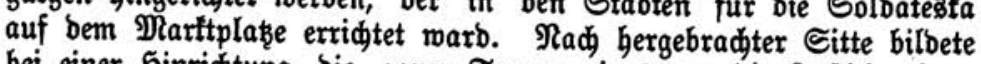
bei einer Sुinridtung bie ganze Truppe rings um bie Juftitia einen Rreia. İ biefem wurbe ber Delinquent vom Racridter herum= gefübrt, um von ben Rameraben 26 fidieb zu nebmen und fie megen feiner Miffethat um '̧erzeibung zu bitten. 3ur Bolfftredung ber Strafe fam eas aber in obigem Falle nidht. P्Ala bie Delinquenten bereits bie Ridtftätte betreten und bie Truppen ben übliden Sireis um ihren Rameraben gebilbet hatten, übte bie ভtabt now im lebsten 2Uugenblid Bnabe. Im Malefizbude befinben fid zwei in ber $\mathfrak{A} \mathfrak{n}=$

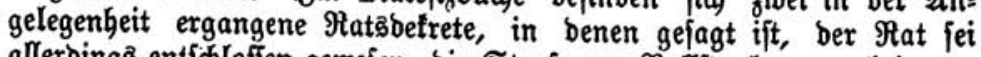

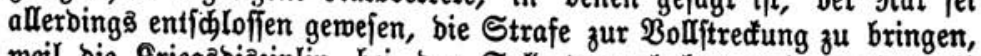
weil bie Sriegåbiąziplin bei ben Soldaten gelodert uno eả beshalb Gödffte Notwendigfeit fei, ein Erempel zu ftatuieren. Troł̧bem habe ex fí, burd bie vorneb̆men und ganz inftänbigen Jnterceffionen, bie für bie Delinquenten eingelegt worben feien und burd bas Elend von

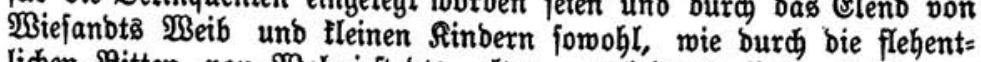
liden $\mathfrak{B i t t e n}$ von $\mathfrak{B}_{0}$ lmirftabts alten "verlebten" Bater bejtimmen Iaffen, ihnen bas \&eben zu fđenten. \$olle Begnabigung exfidien in= beffen bem Rat nidjt angezeigt. Er verbannte bie Piiffethäter auf

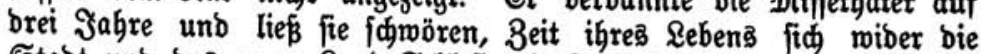
Stabt unb bas ganze \&anb Sdjlefien in Siriegabienjten nidjt gebrauden zu laffen.

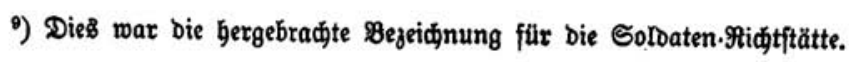


Fünf Jahre barauf wurbe vier anbern Solbaten ber \$rozę ge= madt. 3wei follten mit bem Sdiwert geridtet, bie beiben anbern gehängt werben. Die Tobesiurteile haben benjelben $\mathfrak{B}_{0}$ ortlaut wie bie

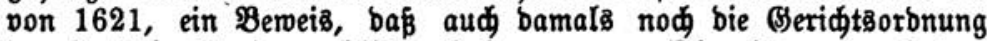
ber \&anostnechte in prattifder Beltung war. Dbrobl nun nad bem

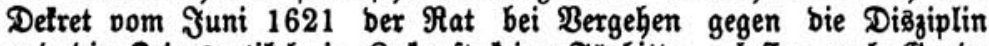
unb bie Rriegsartifel in Butunft teine Fürbitte zulaffen nod Snabe Gatte thben wollen, wurbe ben Delinquenten aud biesmal bas \&eben

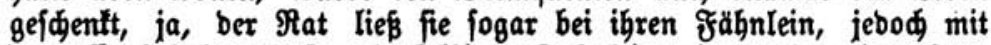

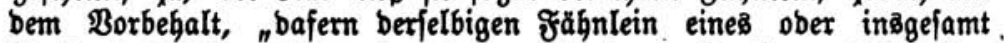
fünftig ins̄ felb rüđen unb mit bem freinbe zu hantieren, Sdladten zu liefern ober zu fळarmugieren, Feftungen, Stäbte, Fleden ober ben

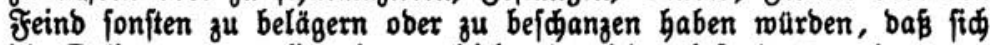
bie Delinquenten alle vier zugleid ober jeber befonbers, wie es an fie gemuthet merben mödte, in aller äuperfter freinbesigefahr (b. h. zu

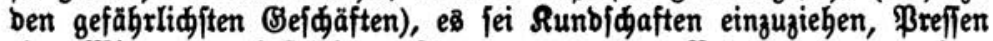
ober Minen zu befidtigen, feuer angutragen, Retraben zu madien, Bruftwebren zu beffern, Sdanztörbe zu füllen, ober was fonft in

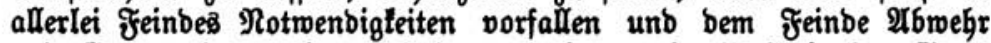
unb BBegentwebr zu thun unb bann aud was inmittelft in ber Stabt nothmenbigen Bauten ihnen auferlegt werben mödte, ganz unweiger= lid, unb ogne allen Entgelt gebraudien laffen follten. Dafern fid aber einer ober alle vier im geringften wiberfpänftig zeigen unb ben in biefer Ridtung an fie ergehenben Befeblen nidt nadtommen würs ben, folle bā̄, ergangene Tobesెurtheil an bem ungehorjamen ogne alle weitere Bnabe volffrectt werben."

So glimpflid verfuhr ber $\Re$ at aber nur bei bişziplinarifden Betgehen. Wegen gemeiner Berbreden ließs er bie exfannten Tobeş= ftrafen zur Bo[fftredung bringen. So wurben (1631) fedis wegen Strapenraubs verurtheilte Solbaten je zu zweien an brei Sanbftrapen in ber $\mathfrak{u m g e b u n g}$ von \$rešlau aufgebängt, uno 1634 ließ̄ er wieberum vier Solbaten wegen beşfelben $\mathfrak{B}$ erbredens vor einem ber Stabttore an einer \$appel aufbängen. 